\title{
The Globalization of Space - The Astrosociological Approach
}

\author{
Marilyn Dudley-Flores ${ }^{*}$ and Thomas Gangale ${ }^{\dagger}$ \\ OPS-Alaska, 2262 Magnolia Avenue, Petaluma, California 94952 USA
}

[Abstract] The primary author coined the phrase "globalization of space" in the 1990s in lectures and presentations, thus the term was conceived in the sociological record. And, though texts and journal articles on sociology are full of studies of the phenomenon of globalization, sociologists are not serious about the study of those aerospatial events that made possible the extent of modern globalization. And, although it is in their purview, they do not keep track of advancements in the aerospace industry that can provide clues to where globalization is taking human societies.

On the other hand, the "globalization of space" is referenced by a host of organizations connected to the aerospace community (i.e., NASA, the Air Force Academy, et al.). However, to the reverse of the sociological community, aerospace organizations have little concept of social factors at varying levels of analysis that can provide clues to where human societies are heading in space - a destination that will impact aerospace industries.

The authors advocate for taking the astrosociological approach, a merging of social science and aerospace perspectives in order to examine the coming benefits and challenges to the globalization of space. Several topics, near-term to long-term, discussed in this report include:

- Demands on the aerospace industry by worldwide human populations affected by global warming, the decline side of oil, and natural disasters in increasingly populated areas

- Ramifications of a return to the Moon

- The need for a new advanced systems management for "big science" problems

- The workings of the technoeconomy-technocracy dichotomy

- Delimitation of the Westphalian nation-state system with the rise of a multi-planet economy

Keywords: globalization of space, astrosociological approach, global warming, decline side of oil, decline of American postsecondary education, outer space production, world system of societies, social investments, technoeconomy, technocracy, transnational partnerships, transformation of capital, ecology of capitalism, technological means of production, Westphalian nation-state system, extraglobalization, multilectic, the solar village

\section{Introduction}

$\mathrm{T}$ HE primary author coined the phrase "globalization of space" in the 1990s in lectures and presentations, thus the term was conceived in the sociological record. And, though texts and journal articles on sociology are full of studies of the phenomenon of globalization, sociologists are not serious about the study of those aerospatial events that made possible the extent of modern globalization. And, although it is in their purview, they do not keep track of advancements in the aerospace industry that can provide clues to where globalization is taking human societies. On the other hand, the "globalization of space" is referenced by a host of organizations connected to the aerospace community (i.e., NASA, the Air Force Academy, et al.). However, to the reverse of the sociological community, aerospace organizations have little concept of social factors at varying levels of analysis that can provide clues to where human societies are heading in space - a destination that may likely impact aerospace industries.

\section{A. About Globalization}

When the primary author first presented the notion of a "globalization of space," at a sociology conference, she bumped into the tussling that goes on over the term "globalization." In many quarters, the term is perceived as a deliberate evil economic process, paraded as natural progress, on the part of connivers in the Western world to lower

${ }^{*}$ CEO/Chief Research Scientist, OPS-Alaska, 2262 Magnolia Avenue, Petaluma, California 94952 USA, AIAA Member.

${ }^{\dagger}$ Executive Director, OPS-Alaska, 2262 Magnolia Avenue, Petaluma, California 94952 USA, AIAA Member. 
trade tariffs to zero (neoliberal manipulators) and to construct a U.S. foreign policy that is aggressive, even militaristic (neoconservative manipulators). When the term is not understood as that, then it is seen as an effort on the part of connivers to harness the natural social forces of globalization to make profits and dominate the world.

We understand the term in this way: Globalization is the growing interconnectedness of all people and their societies on a worldwide scale. It is an emergent multidimensional phenomenon of which issues of economy are only a portion. Although the evolutionary track of globalization can be traced back many centuries, the awareness of the process is relatively recent, which may account for the quibbling over what it is. A kind of global consciousness has emerged as a function of rapid transportation from one continent to another and of information technology. In what has been characterized as the "fifth phase of globalization," begun in the late sixties and which continues today, global consciousness has increased, aided by space exploration (Robertson 1992). ${ }^{1}$ The American space program has, for years, been keen to show consumers how it enhances their lives through such "spin-offs" as Velcro and Teflon. But, the truth of the matter is, engaging the space environment has done far more than giving us a few nifty materials. It has done nothing short of putting the "quantum leap" into the globalization process.

\section{B. Space and Globalization}

Space exploration cultivated the process of miniaturization of instrumentation. The early rockets could carry only a small payload. "Weight reduction was imperative, and the miniaturization of equipment of every kind, including computers, was one of the more obvious solutions (Nolan and Lenski 1999, p. 227)."2 Miniaturization made possible the cascade of advances in computer and satellite technology. It is a bit of an irony that the fifth, or current, phase of globalization has been called "The Uncertainty Phase", for the satellite, landmark instrument of space exploration, allows humans to reflect upon their global image. And, not much is hidden from its detection. It extends the reach and awareness of humankind. Satellite imagery allows us to predict the weather on a global scale. Comsats give us the capacity for instantaneous and easy communication nearly anywhere in the world. A poignant example was the climber on Everest who phoned his wife back home as he lay dying. The satellite is a tool of the global economy. For instance, it tells us if Sri Lanka will have a good tea crop this year and will, therefore, be able to meet its foreign debts. It processes a host of financial transactions.

As an instrument of the Cold War, the satellite aided the end of it by speeding up the process of globalization across several broad categories of interactive phenomena: information technology, ecological effects, social movements and organizations, concern for equal rights, global recognition, the quest for breakthrough ideas, and economic growth. These things have been identified as the key patterns of interaction driving the globalization process (Peterson, Wunder, and Mueller 1999, pp. 16-19). ${ }^{3}$

The computer has been heralded as the landmark invention of the advanced industrial way of life. But, it is the satellite and all that it could do in Earth orbit that provided much impetus behind computer technology. Computers were necessary to the guidance of the rockets that were the satellites' delivery systems; they were needed to track the satellites; and they were needed to process the huge amount of data that came from them. The computer and the satellite are the heart and soul of information technology (IT).

Information technology. This is the technology of communication and information. Of the categories of things that drive the globalization process, this one is the most seminal. For, it increases the frequency of human interactions at an exponential rate. The speed of social change is itself partly a function of the speed and ease of these interactions. Rapid exchange and processing of information contribute to the global erosion of hierarchical structures. Hierarchical structures are the hallmark of tribalism, nationalistic movements, entrenched governmental bureaucracies, and most corporations. This is not to say that the erosion of hierarchical structures will lead to chaos and disorder, as in the total destruction of law and order. What it will lead to is the kind of chaos that physicists and mathematicians speak of, the mathematical chaos that underpins a reordering of a system. The reason the process of globalization is said to be at an uncertain stage has to do with this. With the Cold War over, world societies are experiencing a renegotiation of global civil order. There lies the uncertainty.

The Cold War was all about who would dominate the process of globalization. Fresh in the minds of all "cold warriors" was World War II. The familiar fear of a one-world order imposed by a leader like Hitler got carried over to the fear of global dictatorial hierarchy imposed by the West or the Eastern Bloc, the inheritors of the Heartland of the 1940s world. After the war, paranoia ran high on both sides, each thinking the other was gaining the upper hand, fueled by the megatonage each possessed in their nuclear arsenals. The fear of world domination was incompletely salved by the fear of Mutually Assured Destruction (MAD). And, what would deliver this Mutually Assured Destruction? None other than rockets on suborbital trajectories bound for targets like New York and Moscow, the dreaded Intercontinental Ballistic Missiles (ICBM), courtesy of space research and development.

In the end, the process of globalization itself ended the Cold War. The only "winners" in that war were the societies that had a more open stance toward globalization. The old fear of Mutually Assured Destruction has given 
way to the uncertainty of the re-negotiation period. Non-state actors want in on the renegotiations. They are not a new historical phenomenon. Typically, their troublemaking for state actors had a limited geographic range. But, now they can hook up over the Internet, jet to face-to-face confabs, sneak money around electronically, videograph their bombings and beheadings and videostream them to a world audience, and franchise out with the rapidity of fingers on a keyboard. The Cold War is over - what now? What now, indeed. Information technology and all the other things that drive the globalization process are breeding the new social forms that will make up the re-negotiating global civil order. A world order that, in the decades and centuries to come, will find itself extending off the planet.

Ecological Effects. The struggle to understand the ecology of the planet has certainly led to new social forms. Stewart Brand labeled the space satellite "an engine of the ecology movement (Drexler and Peterson 1991, p. 6)." Imaging the planet, a direct product of space exploration, has enabled our larger awareness of the biosphere. How like fetal imaging it has been! When fetal imaging became possible, the rights of the unborn were championed on a massive scale and abortion issues became a social problem. How like that process has been the images of the Earth from space. While conservation of regional resources was certainly a forerunner of today's environmental movement, conservationism flowered into modern environmentalism owing to imagery from space and other instruments and processes of space research and development.

The first truly global social movement is environmentalism. And, such movements have led to new social forms. And, we may expect other social forms to emerge as we grapple with the truly huge national boundarycrossing (transnational) problems of the decline side of oil, the epochal climate change that comes with global warming, and natural disasters in ever-increasing populated areas.

Social Movements and Organizations. Whether we are speaking of more established social movements and organizations or emerging ones, none of these would be able to meet their goals today without information and communications technologies. High-tech industries have spurred trends in networking and cooperative organization. A "spin-off" of the environmental movement is an understanding of how ecosystems are organized and these are turned to for models for the human ecology. We speak of the "organic" growth of non-state actor organizations. And, as most commentators on globalization have remarked, much about the social formations of our modern world is characterized by "network" structures diffused from both the biological world and the worlds of broadcasting and the World Wide Web.

Concern for equal rights. With communication that permeates national boundaries, there is an awareness among people throughout the world of each other's living conditions. While globe-trotting journalists and early radio and television did plenty toward this end, satellite broadcasting and the Internet have brought a hard reality, a sense of urgency, and a next-door-neighborliness that Marshall McLuhan called in the sixties "the global village". The global village has never been so real as it is now. The atrocities of those nationalities that battled in the Balkans were like atrocities against your own neighbors.

This breeds a concern for equal rights that doesn't require the nicety of abstract thought to comprehend. It comes from a concrete level of seeing something as it happens with one's own eyes. And, from this, we learn to care not only for those getting hurt and disrespected in distant places, but for all individuals in all places in all aspects of their lives, their pains and their joys.

Global recognition was once reserved for nation-states and rare others. It is now being extended to the individual. This process gets at the taproot of innovation. While modern communication and transportation have made available the teachings and technologies of the world's cultures to nearly everyone, it also makes available the wacko ideas of Rudy the Skinhead and Leroy Bandanna, as well as Joe Six-Pack making a better mousetrap in his basement. Of course, some shoppers in the great Mall of Ideas will not be able to discern the bad merchandise from the good and roll their carts down the aisles of intellectual and evolutionary dead-ends. But, most folks will not be suckered. They will know the difference between the teachings of Martin Luther and the writings of the Unabomber; the teachings of the Buddha and the ravings of teenage boys in trench coats with guns in their book bags. They will shop and compare, and most importantly, compare notes. It is a mathematical inevitability that deeper global understanding in all its many facets - and those yet to be discovered - will emerge. The quest for breakthrough ideas is in no danger of being called off.

The quest for breakthrough ideas. The infrastructure that has spread from the satellite and the computer is the Gutenberg Press of our time. And, it was all made possible by the human exploration of space.

One such truly breakthrough idea is molecular nanotechnology that could, virtually overnight, change technology as we know it. Nanotechnology techniques can construct materials and alter the structure of matter at a molecular level. Nanotechnology is the logical extension of the miniaturization effort that began in the early days of space exploration. While we are nowhere near that overnight transition, we are certainly able to conceptualize about nanotechnology and its applications now. Without computer technology inspired by space exploration, we could not 
ever develop nanotechnology. That's because this technology will require a vast quantity of data to be processed and a great deal of memory storage.

What about economic growth and the global economy as we know it in the present? This is usually the phenomenon that most people associate with globalization. It emerges from of all these categories of interactive phenomena. Only an interdependent global economy could provide the capital mass or the financial avenues to bankroll the application of breakthrough ideas, truly effective global organizations, the enhancement of each individual, to assess the environmental degradation and climatic shift of a whole planet and repair it, and to extend the human ecology to other venues.

\section{The Globalization of Space}

Space exploration does not stand apart from the globalization process. It is part and parcel of the thing it has magnified. The globalization process, therefore, requires us to re-think the exploration of space. Societies leapfrogging to advanced industrial status like China and India are getting in on outer space production. And, because they have many blueprints to follow from those societies that have gone before, they can be expected to make a sharp gradient of progress once they get going. Will they cooperate with each other and with a variety of others or compete one-against-all? One thing is certain: the two traditional competitors of the Cold War and the Space Race are doing a lot more cooperation these days, as are their many allies. There is an historic trail to their collaborations, stepping to increasingly longer duration space missions.

Anymore, long-duration space operations are necessary to almost anything of value done in space, regardless of it being a robotic or manned mission. Mastering long-duration space exploration is a prerequisite to human permanency in space, which is nothing short of the expansion of the human ecology off the Earth. Yet, on the verge of longer-duration missions, as in a manned mission to Mars by the United States, conceptualized for the 1980s, events of American history intervened - namely in the form of the decisions of the Nixon administration. In the meantime, the potential for global manmade destruction in the form of nuclear madness has been replaced with the decline side of oil, global warming, and large-scale natural disasters in ever-increasing populated areas. Nukes are no longer the concern they once were, but Nature and how humans stand in relation to her sure are. Once again, humanity wonders if it will survive. The things that matter most now are the answers to these questions:

- How do we power this world system of increasingly advanced industrial societies without petroleum?

- How do we mitigate, adjust to, or solve for rising sea levels and other direct and indirect effects of global warming?

- How do we mitigate natural disasters that occur in parts of the world becoming ever more populated and infrastructure'd?:

How does "globalized space" help answer those questions? This is the significance of the inquiry into the globalization of space. If space exploration can play a large role in the answers to those questions, it will be able to get out of first gear and lead to the expansion of the human ecology on this world and in places off the Earth. Space must become demonstrably relevant to a wider global audience interested in survival. It no longer can be about just Tang, Teflon, and Velcro or even just about ICBMs and spy satellites. It has to be about making the scientific and technological explorations to ensure energy production, to guarantee surviving and thriving during an epochal climate change, and offsetting natural disasters.

In a departure from the authors' usual framework, let us introduce you to our methods of inquiry at this juncture. They are as follow.

\section{Methods}

Our social science perspectives wedded to our engineering and natural sciences perspectives are our methodology in this report. The authors specifically like to think of the proposed discipline of astrosociology as being "social factors" engineering benefiting from sociology, just as "human factors" engineering has benefited from psychology. Human factors engineering has typically installed in the engineer enough psychological

\footnotetext{
* When one factors out manmade disasters like those of war, terror, and accidents of poor design, usage, and upkeep, one is left with natural disasters. Natural disasters will occur so long as we live on a planet and are human: disease, severe weather, earthquakes, tsunamis, volcanic eruptions, Near-Earth object strikes, and even some more exotic phenomena and permutations thereof. The effects of global warming might worsen some of those disasters, like bigger hurricanes and typhoons.
} 
knowledge to design a human-rated instrument panel in an aircraft, a computer keyboard for the user, or a soldier's body armor. Astrosociology holds the promise of installing enough technological consciousness in the sociologist and enough social and societal consciousness in the engineer so that they may work seamlessly on the thing that matters most to the human lineage - its survival safely on this planet and its ensured survival through its expansion of the human ecology off of the planet. Astrosociology is not, as some sociologists have argued from their tiny compartmentalizations, just another tiny fragment of sociology. Astrosociology is an instrument of integration -attempting to integrate across sociology and other disciplines and bridge to the minds of natural scientists and engineers to assist them in ensuring the survival of the species (Dudley-Flores and Gangale 2007). ${ }^{5}$

Our social science perspectives hail from a social scientific domain of study concerning social change. Typically, archaeologists, sociologists, and "society and technology" scholars ponder the weighty questions of what make societies change. Their approaches are usually quite comprehensive, running up and down the scale of macrosocial, mesosocial, and microsocial phenomena that comprise social change. Their perspectives involve the consideration of a human timescale and are structural, examining the opportunities and constraints of social structures at any given moment. The elements of structure and process/interaction are inherent to these approaches. Not an exclusive list, three such perspectives are:

- Immanuel Wallerstein's World Systems Theory

- Otis Dudley Duncan's POET model, and

- Patrick Nolan's and Gerhard Lenski's Ecological-Evolutionary Theory

World Systems Theory. While generally applied to characterize nation-states and large geographic regions of the world, we have seen this theoretic approach applied to different parts of large cities, to regions within the United States, and to towns along interstate highways. To apply it to a region or a collective of municipal units, requires the selection of major diagnostic factors such as infant mortality per capita, number of airports, numbers of graduate degrees per capita, or any other collective of diagnostic units pertinent to a phenomenon being studied. One may view these diagnostic factors as "structural codes" that total up the standing of one area in relation to another. Wallerstein views the world connected by a complex network of economic exchange relationships - i.e., a "worldeconomy" or "world-system", in which the dichotomy of capital and labor, and the accumulation of capital by competing actors (historically including, but not limited to, nation-states) account for conflicts. He places the origin of the modern world-system in 16th-century Western Europe and the Americas, with only one global system of economic exchange extant today -- the capitalist world-economy. An enduring division among core, semi-periphery and periphery areas marks this world-economy. External areas that have managed to remain outside the worldsystem, enter it at the peripheral stage. There is a fundamental and institutionally stabilized division of labor between core and periphery. While the core has a high level of technological development and manufactures complex products, the role of the periphery is to supply raw materials, agricultural products and cheap labor for the expanding actors of the core. Economic exchange between core and periphery takes place on unequal terms: The periphery is forced to sell its products at low prices, but has to buy the core's products at comparatively high prices, an unequal state which, once established, tends to stabilize itself. The statuses of core and periphery are not, however, mutually exclusive and fixed to certain geographic areas; instead, they are relative to each other and shifting. The intermediary zone, the semi-periphery, acts as a periphery to the core, and a core to the periphery. At the end of the twentieth century, this zone was characterized by Eastern Europe, China, and Brazil. Peripheral and core zones can also co-exist very closely in the same geographic area. One effect of the expansion of the worldsystem is the continuing commodification of things, including human labor. Natural resources, land, labor and human relationships are gradually being stripped of their intrinsic values and turned into commodities in a market that dictates their exchange value. ${ }^{\S}$

The POET Model. The "structural codes" of the POET Model are (P) Population, (O) Social Organization, (E) Environment, and (T) Technology. The interaction of these codes can be examined to characterize the state and progress of any particular social/societal phenomenon at any level of analysis (Duncan 1959). ${ }^{6}$

The Ecological-Evolutionary Theoretic Approach. This approach is concerned with two categories of things:

- The relations among parts of societies and with the interactions between societies and their environments; and

${ }^{\S} \mathrm{http}: / /$ en.wikipedia.org/wiki/Immanuel_Wallerstein 
- The evolution of societies, with a particular emphasis on the impact of subsistence technology on the fundamental features of societies, and on the impact of constraints that the techno-economic heritage of industrializing societies continue to exercise on their development trajectories.

The interplay of "structural codes" used in application of this perspective is 1) population, 2) culture, 3) material products, 4) social organization, and 5) social institutions (Nolan and Lenski 1999). ${ }^{7}$

\section{History of Ideas}

\section{The World System of Societies in Space}

An overt example of the globalization of space is the International Space Station (ISS). There are many things that this space station is not, as will be discussed below. However, the greatest benefit to derive from it that helps answer the problems of Earth is its role in an important paradigm shift. It has continued a paradigm shift that began with the Apollo-Soyuz Test Project. That paradigm shift was the transition from a competition in space between the Soviet Union/Russia and the United States, to a stance of cooperation. The Apollo-Soyuz Test Project (July 1975) was the first joint flight of the American and Soviet space programs. ${ }^{* *}$ The Test Project allowed for the synchronization between American and Soviet/Russian space technology that informed the NASA-Mir collaboration (1994-1998). Similarly paradigm-shifting has been the European Space Agency's (ESA) and NASA's Spacelab collaborations that have continued intermittently on board space shuttle flights between 1983 into the early 2000s. Also, beneficial have been the many international inputs through the American and Russian sides by other national space programs. A salient example is Italy's Harmony Module that will connect Japan's Kibo Laboratory Module and the European Space Agency's Columbus Module to the International Space Station (the latter module a collaboration among French, German, and Italian companies and facilities).

Even among some government executives, it is widely billed that the ISS is an American-sponsored project where we "permit" the space agencies of other nations to participate. This is a gross oversimplification. We wouldn't be able to have much of a space station without our Russian partners. It is an historical fact that the United States had to talk them into de-orbiting their beloved Mir to focus their effort to help us get the ISS up and running. And, we very much wanted them to honor their partnership. That is because there was much they were able to contribute from their generations of space station expertise that we did not possess, and that would have taken time

Evolution of Leading Space Budgets : 1980-2003

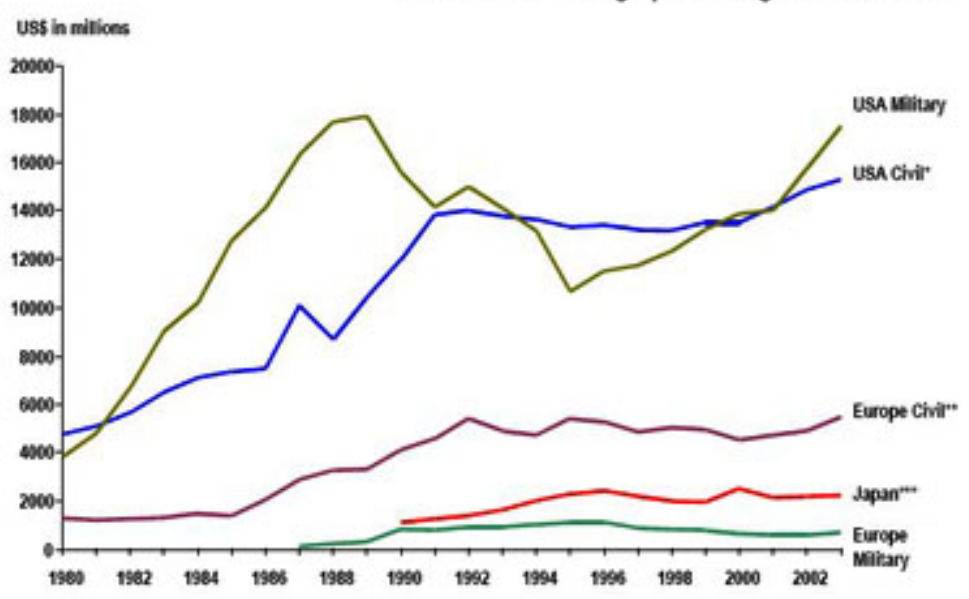

Figure 1. Leading Government Space Budgets, 1980-2005 Source. www.spacedaily.com/news/satellite-biz-03zzzl.html to develop and to set up the necessary manufacturing infrastructure.

Without willing collaboration, the civilian space endeavor worldwide would not be as far along as it is today. Those who look fondly back at the competitive days of the Space Race and yearn for another one, miss the mathematical fact that the principle of diffusion, another driver of innovation, works better when it is unimpeded. Even the Russian long-duration Humans-to-Mars effort is an international, inter-agency, intercorporate array of projects. It is a "makework" enterprise made possible through the auspices of an international non-proliferation program, the International Science and Technology Center (ISTC), that spends a few million dollars a year on former Soviet scientists and engineers to keep them from leaking their weaponizable expertise and materiel to "evil axis" states and terror warlords. The ISTC is an intergovernmental organization headquartered in Moscow, Russia, and whose governing board is chaired by Ronald Frank Lehman II, the Director of the Center for Global Security Research at the Department of Energy's Lawrence Livermore National Laboratory. ${ }^{\dagger \dagger}$ NASA and the ESA are partners in this "transgovernmental" organization and Boeing is the big industry player.

\footnotetext{
${ }^{* *}$ It was the last Apollo flight and last manned space launch until the flight of the first space shuttle in April 1981.

${ }^{\dagger} \mathrm{http}: / /$ cgsr.llnl.gov
} 
China (also a contributor to the International Science and Technology Center) has also wanted to participate aboard the International Space Station. However, the way to that collaboration has been full of ups and downs. SinoAmerican cooperation on space technology took a nosedive in 1996, after Loral Space \& Communications Corporation was found to have forwarded a report on a Chinese rocket to the Chinese government without first obtaining U.S. State Department clearance, a situation that led to a grand jury investigation. In late 2002, the State Department accused Hughes Electronic Corporation of giving the Chinese key information to assist them in determining why their rockets tended to fail soon after launch. The incident had occurred in the 1990s at the high point of concerns over the transfer of sensitive satellite technology to the PRC. However, in time, the move to increase sales of satellite technology to China gained momentum. The State Department loosened rules on export of scientific satellite projects to the PRC in April 2002. Six months later, Chinese head of state Jiang Zemin met with President George W. Bush to discuss easing bans on the transfer of satellite technology if China reduced its sales of missile technology to third parties. While the two leaders did not reach an agreement, talks continued. Then, on March 28, 2003, a missile fired by the Iraqis hit a shopping mall in Kuwait. The weapon was a modified Chinesemade Silkworm rocket. ${ }^{+1}$ By the time China orbited Lieutenant Colonel Yáng Lìwěi in October 2003, the opportunity had emerged for astronautic competition between it and others. On 11 January 2007, China used a ground-based medium-range ballistic missile to destroy its Feng Yun 1C polar orbit weather satellite. Taiwan's senior politicians registered the most protest. U.S. spy satellites observe the Taiwan Straits, which are useful to coordinating any defense of Taiwan in the case of a Chinese invasion. ${ }^{\S \S}$

India has had a steady-growth space program and has cooperated with the European Space Agency, NASA, Soviet and Russian space programs, and smaller national space agencies since the 1960s. It has made great progress. In January 2007, the Indian Space Research Organization (ISRO) mastered "splashdown" technology in the Bay of Bengal. ISRO has announced plans to launch an all-Indian crew into space by 2014.

The European Space Agency has spent very little budget on manned spaceflight, collaborating with the United States and Russia to get its astronauts to space. It has shown little interest in lunar endeavors, but has a timeline established for a European Mars mission scheduled by or around 2030. It is working on a counterpart of the Crew Exploration Vehicle (CEV) and other "beyond Low Earth Orbit" designs with Russia. It teamed with the China National Space Administration (CNSA) in 2003 and 2004 on the Double Star satellites that study the Earth's magnetosphere. The ESA is probably the most collaborative of all the space agencies, and we will discuss this characteristic more below.

\section{E. Outer Space Production and the Roles of Non-Governmental Enthusiasts, Private Entrepreneurs, and Government}

Since the traditional treatments of globalization focus on its political-economic aspects, and since our current phase of globalization has depended on aerospace production, let us take a look at the political-economic picture that bears on the future of the globalization of space - all other things being equal.

An activist citizenry has a positive role to play in promoting the "outward course of empire" (Dudley-Rowley 1999), ${ }^{8}$ in inculcating a general awareness that outer space is already an important sector of the global economy, and that the importance of outer space will continue to grow. This might have small effects on technoeconomy, educating entrepreneurs on the possibilities of outer space for profit-making enterprises. As threads in the fabric of the emerging civil society of outer space, they can be a valuable adjunct to the professional aerospace organizations, speaking as "the people," rather than as groups with obvious vested interests. Not having self-serving agendas accords them a certain specie in the corridors of power, an ability to be a faint, but uncorrupted voice in the wilderness. Operating in this venue, they can have an impact on technocratic decisions.

However, space enthusiast groups also have the defect of their virtue. They can be founded on certain unquestioned basic assumptions that should have been and ought to be questioned. As a case in point, the L-5 Society's misinterpretation of the Moon Agreement set it up to be co-opted into a corporate-led effort whose real target was the Law of the Sea Convention, whereas the torpedoing of the Moon Agreement was arguably against the interests of outer space development, the very mission of the L-5 Society (Gangale 2006). ${ }^{9}$ Space enthusiast organizations can be insular and polarized, preaching to their own choirs, either damning NASA, the major aerospace contractors, or the government-industrial complex in general as the Forces of Darkness, or singing hosannas to them as the Givers of Light. Often, the governance of these organizations is saddled with self-appointed

\footnotetext{
\# "Satellite Technology Exports to the People's Republic of China (PRC)," by Judson Knight, http://www.espionageinfo.com/Re-Se/Satellite-Technology-Exports-to-the-People-s-Republic-of-China-PRC.html $\$ \&$ "China Confirms Satellite Downed," BBC News, http://newsvote.bbc.co.uk/mpapps/pagetools/print/news.bbc.co.uk/1/hi/world/asia-pacific/6289519.stm
} 
presidents for life. These organizations tend to resemble personality cults, where the imams of outer space hawk their poorly-vetted ideas year after year as they are superseded by events. For any of theses reasons, ultimately, such groups are self-limiting and transient phenomena, reaching a maximum altitude then falling to Earth (Michaud 1986). ${ }^{10}$ They soon squander whatever specie they might have had with policymakers at the outset. The founding conventions of these organizations may be well attended by optimistic professionals from government, industry and academia, but after a few years, being associated with these groups can be as dangerous to one's career as dressing up like Marvin the Martian and chaining oneself to the White House fence.

The citizen space community is small, fractured, and appears to lack a cohesive core of expertise. The pool of expertise that it possesses is diffused among a general population of enthusiasts, which makes it difficult to focus that expertise to a productive purpose. In a positive development, the American Institute of Aeronautics and Astronautics, a professional organization that draws its membership from industry, government, and academia, has begun to increase its efforts in the policy arena, both through its annual Congressional Visit Day and through greater visibility of its Public Policy Committee. The citizen group ProSpace's annual "March Storm" on Capitol Hill is a noble effort; however, an informed voice that speaks both to civil society and in the corridors of power is sorely needed.

The general public is ignorant of space to a large degree. As a society, we have a poor understanding of our place in the solar system: the relative distances between Earth, the Moon, the sun, and the various planets and their moons; the relative sizes of these celestial bodies; the environmental conditions on them. In 2003, author Gangale observed firsthand how bogus satellite imagery of the 1 February destruction of Columbia and the 14 August electrical blackout of the northeastern US and eastern Canada passed uncritically through the email system among engineers at one of the nation's largest utility companies. One would have thought that such technically-trained people would not have been so easily duped. Jim Pass' $(2004)^{* * *}$ distinction is apt; we have yet to become a true spacefaring civilization, we are merely a space-capable civilization.

The public generally supports the civil human space program, although it has little knowledge of what it is actually doing. And not only does the public not know what it is getting for its tax dollar, neither does it have any idea of what it is paying for. Polls show that the only about ten percent of the public correctly estimates that the National Aeronautics and Space Administration budget represents less than one percent of federal spending, whereas approximately twenty percent of the public believes that the NASA budget accounts for more than a quarter of federal expenditures (Launius 2003). ${ }^{11}$ This suggests that there would be much greater support for the civil space program if the public knew what a bargain they were getting, and might support spending levels several times higher than the actual ones.

A number of space enthusiasts tout free enterprise as the wave of the future in space development, and take great delight in disparaging government space projects as building the wrong capabilities for too much money. These detractors are "space cowboys" with big hats and no cattle. The authors have no doubt that free enterprise will be important to space development, but we have grave doubts that it will have a significant impact in the near future. Yes, government programs are expensive, because there are extraordinary engineering challenges to getting into space on the cheap.

It is one thing to accelerate to $3,500 \mathrm{~km} / \mathrm{hr}$ and poke one's head above an arbitrarily defined threshold for a few seconds, as SpaceShipOne did in 2004. At the top of that steep parabola, horizontal velocity was near zero. It is orders of magnitude more difficult to reach half again as much altitude and simultaneously accelerate to a horizontal velocity of $29,000 \mathrm{~km} / \mathrm{hr}$. Even more important is the requirement to withstand the deceleration and heat-loading of reentry from orbital velocity. A rudimentary calculation will serve to demonstrate. The ratio of orbital velocity to the peak velocity of SpaceShipOne is 8.3 to 1; however, the energy is a function of the square of the velocity, thus the energy ratio is 68.7 to 1. Clearly, the total heat-loading experienced by SpaceShipOne is inconsiderable compared to return from orbit. Solving these problems in the context of a credible business model is decades away.

Some have defended the libertarian vision of private space development by mentioning such things as the federal Homestead Act. The SpaceShipOne flights are supposed evidence that private space tourism is not far in the future, and that private space travel to the Moon or Mars is not hopelessly romantic. The use of in situ resources, inflatable habitats, nanotechnology, and advances in computer tech/robotics should bring unanticipated capabilities and cost reductions.

\footnotetext{
*** Pass, Jim. 2004. "Space: Sociology's Forsaken Frontier.” Internet. Available from http://www.astrosociology.com/Library/PDF/Submissons/Space_Sociology’s\%20Forsaken\%20Frontier.pdf
} 
And so might pixie dust. Engineering solutions are based on technology in hand, not unobtainium beyond the horizon. The question is: "When?" Some space enthusiasts point to the rapid improvements in computer technology-and the huge commercial industry it has spawned - as a model for projecting a coming explosion in commercial space travel. The authors urge caution. Nanotechnology is nothing more than the extension of Moore's Law from the micrometer realm into the nanometer realm. It has been anticipated for decades. It does not represent a sudden, steep upswing in the rate of technological progress. There was none during the computer revolution in the late ' $80 \mathrm{~s}$, early ' $90 \mathrm{~s}$; it was steady, incremental progress. Moore's Law of doubling chip capacity every two years has held for 40 years.

Now, here is the really bad news: there is no aerospace analogue to Moore's Law. There is no evidence that the cost per mass to orbit reduces by half over a specified time scale. In fact, the cost per mass to orbit remained virtually unchanged from 1994 to 2000 inclusive, a 7-year period. A September 2002 report by Futron Corporation concludes $^{\dagger \dagger \dagger}$ :

Regarding [non-geostationary orbit] launch prices, there is no clear trend in the price-per-pound metric, other than a clustering around $\$ 10,000$ per pound in the late 1990 s. While this is lower than GSO launches, it is not as low as one might expect....

At best, a linear trend might be inferred from the 1990-2000 data for Geostationary Orbit (GSO). Regressing the 1990 average of $\$ 40,740 / \mathrm{kg}$ and the 2000 average of $\$ 25,804 / \mathrm{kg}$ yields an average cost reduction rate of $\$ 1494 / \mathrm{kg} / \mathrm{yr}$. The cost per mass to LEO is less; however, the cost of operating a humanrated system is much higher because of the requirements for life support systems, higher reliability and safety standards, and most importantly, return capability. But let's be very charitable and assume that the cost of per mass of a human-rated system to LEO is the same as the cost per mass of a non-human-rated system to GSO (we doubt this is true, but consider it a government subsidy from the "Gangale Republic"). The cheapest human-rated Earth-to-orbit transportation system around (indeed, the only one operating at the moment) is the Soyuz 7K-STMA, which has a mass of 7,220kg and can carry one paying passenger. At the 2000 average of $\$ 25,804 / \mathrm{kg}$, a Soyuz flight should cost $\$ 186$ million. Actually the going price for a Soyuz joyride has been about $\$ 20$ million. Obviously, the commercial passenger is not bearing the full cost of the flight; he is just buying a seat and is just along for the ride, whereas the crew has a real mission to perform. This is not the paradigm of a commercial, profit-making venture.

But, let's take a flight of fancy and say that the Gangale government is going throw in another subsidy, and match the Russians' price of $\$ 20$ million per seat. That is still sky-high (no pun intended). How is the stars-in-hiseyes space entrepreneur going to get the average person to subject himself to having his eyeballs shoved against the back of his skull and then have his stomach float up to his chest (not to mention the contents thereof floating about the cabin) for less than $\$ 2000 ?^{\text {?t* }}$ Bringing the spouse/domestic partner along doubles the price; bringing the kids just about doubles it again.

So, we need to reduce the seat cost from $\$ 20$ million to $\$ 2000$, a difference of $\$ 19,998,000$. At an average cost reduction rate of $\$ 1494 / \mathrm{kg} / \mathrm{yr}$, that will take 13,400 years. But, as a final concession, let's throw in some unobtainium from the Gangale Republic's strategic reserve, and reduce this time-frame by an unbelievable $99 \%$. That will bring space tourism within reach of the average consumer in 134 years.

Here is another back-of-the-envelope calculation, much shorter, and with much less substantiation. Starting with the estimated full cost of a Soyuz flight, $\$ 186$ million, and assuming for the sake of wild optimism the emergence of an aerospace analogue to Moore's Law with a time constant of 5 years (again, there is absolutely no historical basis for this), the $\$ 2000$ seat would become available about the year 2090.

Here is a reality check from an independent source. In a September 2006 discussion with Apollo astronaut and former L-5 Society president Philip K. Chapman, he expressed the hope that the cost per pound to orbit could be reduced to $\$ 1000$ in the next 20 years, possibly even as low as $\$ 500$. No one wants to see space commercialization succeed more that Chapman. Before we try to translate this into the price of a seat, let us look at the historical data for orbital spacecraft mass versus maximum occupant capacity (Table 1).

1† Futron Corporation. 2002. "Space Transportation Costs: Trends in Price Per Pound to Orbit, 1990-2000." 6 September. Internet. Available from http://www.futron.com/pdf/FutronLaunchCostWP.pdf; accessed 21 January 2006.

t\# Gangale has a few hours in fighter aircraft, and there is nothing comfortable about this kind of flight regime. 


\begin{tabular}{|l|l|l|l|l|l|}
\hline Spacecraft & $\begin{array}{l}\text { First } \\
\text { Manned } \\
\text { Flight }\end{array}$ & $\begin{array}{l}\text { Launching } \\
\text { State }\end{array}$ & $\begin{array}{l}\text { Mass } \\
\text { (kg) }\end{array}$ & $\begin{array}{l}\text { Maximum } \\
\text { Occupants }\end{array}$ & $\begin{array}{l}\text { Mass per } \\
\text { Occupant } \\
\text { (kg) }\end{array}$ \\
\hline Vostok/Voskhod & 1961 & USSR & 5,682 & 3 & 1,894 \\
\hline Mercury & 1962 & USA & 1,118 & 1 & 1,118 \\
\hline Gemini & 1965 & USA & 3,851 & 2 & 1,926 \\
\hline X-20A Dyna-Soar & $1966^{1}$ & USA & 3,600 & 1 & 3,600 \\
\hline Soyuz & 1967 & USSR & 7,250 & 3 & 2,417 \\
\hline Apollo & 1968 & USA & 5,806 & 3 & 1,935 \\
\hline Transportnij Korabl Snabzheniya & $1981^{2}$ & USSR & 17,510 & 3 & 5,837 \\
\hline Space Shuttle & 1981 & USA & 99,117 & 7 & 14,160 \\
\hline Buran & $1994^{3}$ & USSR & 42,000 & 10 & 4,200 \\
\hline Shenzhou & 2003 & China & 7,840 & 3 & 2,613 \\
\hline Orion & $2014^{4}$ & USA & 13,886 & 6 & 2,314 \\
\hline
\end{tabular}

\section{Table 1. Manned Spacecraft}

Notes.

${ }^{1}$ Schedule at time of program cancellation in December 1963.

${ }^{2}$ Schedule at time of program cancellation in January 1978.

${ }^{3}$ Schedule at time of program cancellation in June 1993.

${ }^{4}$ Schedule as of October 2006.

Early manned spacecraft had little to no capability for the significant orbital maneuvers that would be required for a commercial passenger vehicle taking people to an orbiting space hotel. They also had few of the amenities that a commercial passenger would expect for a comfortable flight. Even so, let us take the lowest spacecraft mass per occupant (Mercury, at $1,118 \mathrm{~kg}$ ) and Chapman's more optimistic figure of $\$ 500$ per pound, and without even considering a cost factor for a man-rated system (additional safety requirements, life support systems, et cetera), the calculation yields:

\section{$1118 \mathrm{~kg} \times 2.2 \mathrm{lb} / \mathrm{kg} \times \$ 500 / \mathrm{lb}=\$ 1,229,800$}

This is the best-case, low-ball, no-frills fare... 20 years from now. A more reasonable estimate would double the mass per occupant and double the cost per unit mass, yielding $\$ 5$ million per seat.

One of the largest factors in determining the cost per mass to orbit is the mass fraction of payload to total launch mass. This can be improved somewhat by efficient structural design to reduce tankage mass, turbopump design, engine pressure, and some other things. However, these gains are small compared to the theoretical constraints on reaction mass exit velocity, which are a function of chemical bond energy. Reaction mass exit velocity is expressed as specific impulse, $\mathrm{I}_{\mathrm{sp}}$. NASA/Glenn has a webpage ${ }^{\S \S}$ that does a nice job of explaining it.

The higher the $\mathrm{I}_{\mathrm{sp}}$, the more energy the fuel/oxidizer combination has, and the greater the mass fraction. The theoretical $\mathrm{I}_{\mathrm{sp}}$ limit for a hydrogen/oxygen bipropellant is around $460 \mathrm{sec}$, which is one of the highest [chemical $I_{\mathrm{sp}}$ 's] there is. Solid monopropellants are usually around 200-250 sec; however, the fact that solids are cheaper to manufacture and easier to handle offsets their poorer performance. A higher $\mathrm{I}_{\mathrm{sp}}$ is a lithium-fluorine-hydrogen tripropellant $(540 \mathrm{sec})$, but fluorine is so corrosive that no one wants to mess with it; it would be so horribly expensive in the operational environment as to more than offset performance gains. Also, no one wants to use nuclear engines $\left(I_{\mathrm{sp}}=850 \mathrm{sec}\right)$ in Earth's environment, and some don't want to use them at all, so at best they would be restricted to use as transorbital stages. Ion engines are very high $\mathrm{I}_{\mathrm{sp}}(3000 \mathrm{sec})$, but very low thrust devices, good for motoring around the solar system, but no good at all for getting onto or off of a planet.

When Gangale was in engineering school at the University of Southern California 30 years ago, he read a fascinating article, either in Aviation Week and Space Technology or the AIAA's Astronautics and Aeronautics, about metallic hydrogen, in which theoretical $\mathrm{I}_{\mathrm{sp}}$ 's of 1,000 to 1,600 sec were discussed. He thought he'd take the conservative figure of $1000 \mathrm{sec}$ and design a lunar tug around it. His professor said exactly two words before he

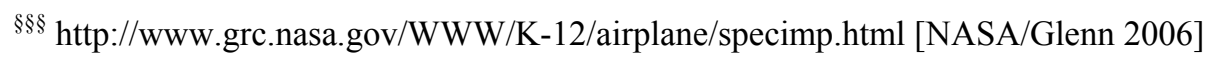


turned away: "Totally unrealistic." He was right. 30 years later, Gangale hasn't heard of metallic hydrogen as a propellant since, and we're still screwing around with the same $\mathrm{I}_{\mathrm{sp}}$ 's we had 40 years ago. Why? Simple. The fundamental laws of chemistry have not changed in 40 years. We have been operating near the theoretical limits all that time, and there is no way past them. There is always a way to make a smaller circuit, but it is impossible to get more energy out of a chemical reaction. That is why there is no astronautical analogue to Moore's law.

Space is an extreme environment, in which humans and their engineering systems operate at the margins. The best analogue for spaceflight is not the personal computer, nor even the private aircraft, but the submarine. Submarines have been around for more than a century, yet there is no commercial submarine travel industry.

The golden decade of the 1960s has long since faded, and has been followed by more than three decades of disappointment and disillusionment in the space enthusiast community. If this community expected the US to continue to devote $4 \%$ of the federal budget to the civil space program (versus the $1 \%$ average since), the expectation was unrealistic. ${ }^{* * * *}$ Not to have realized the limitations of technocracy at the time was naive, but understandable; failure to understand this several decades later is denial, which is inexcusable. To promote privatization as the panacea is to misunderstand the relative strengths and weaknesses of technocracy and technoeconomy. Responsible space advocacy requires an understanding of the political-economic forces that have brought us to where we are today, so that we can develop a coordinated strategy to harness these forces to best advantage to propel us toward the kind of future we want.

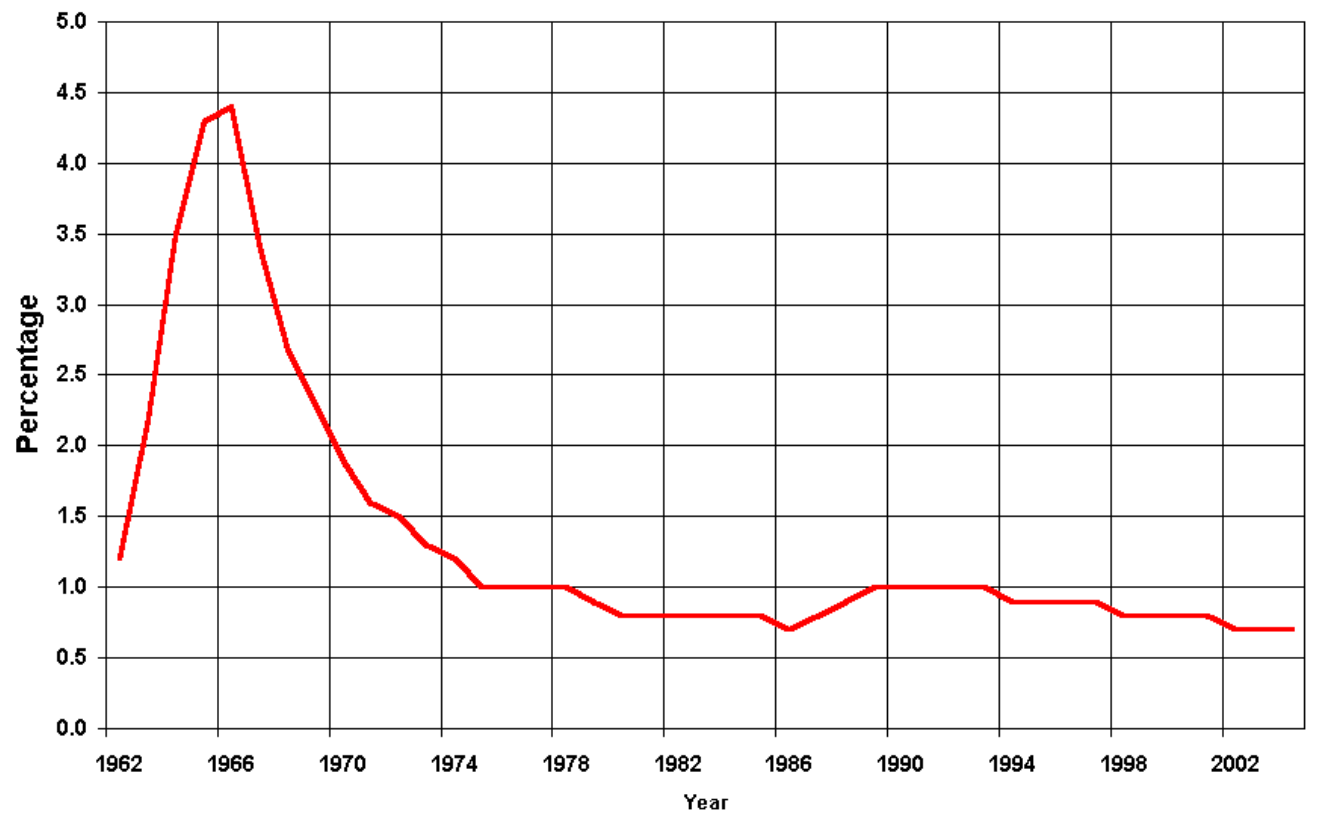

Figure 2. NASA Budget as Percentage of Federal Budget, 1962-2004

Source. www.asi.org/images/2003/NASA-budget-as-percentage-1962-2004.png

Technocracy, which is the state-directed "force-growing" of specific technologies to serve state interests, can achieve spectacular results in a short period of time. The problem with technocracy is its narrow focus - in time and in purpose. The purpose is power, not wealth. The time span is usually a few years-lasting only as long as it takes to achieve state interests, and the project is terminated once it no longer serves those interests. There may be residual economic benefits from the project, but these are incidental and are not the justification for the resources invested. The calculus is political, not economic.

\footnotetext{
**** Presidential candidate Rep. Dennis Kucinich of Ohio proposed tripling the NASA budget. (Kucinich, Dennis. 2004. "Kucinich Says NASA's Budget Should Be Tripled." Space Daily, 9 May. Internet. Available from http://www.spacedaily.com/news/nasa-04j.html; accessed 30 January 2006.) He garnered only 3.8\% of the primary vote nationwide and received only 17 of the total 2,719 delegates to the 2004 Democratic National Convention. (Cook, Rhodes. 2004. "2004 Nationwide Democratic Primary Results and Delegate Count." Internet. Available from http://www.rhodescook.com/primary.analysis.html; accessed 6 January 2006.)
} 
Technoeconomy is the "organically grown" technologies developed for the market. These also serve a narrow interest - producing profit for the investor - but that purpose is long-lived. The project lasts as long as there is a market for the product line. As the science fiction author Poul Anderson had his space entrepreneur Nicholas van Rijn say, "Politics, they come and go, but greed goes on forever (Anderson 1963)."12

Technocracy and technoeconomy each have their strengths and weaknesses, and to a large degree they compliment each other. It is a fundamental mistake to compare the accomplishments of technocracy and technoeconomy. "If we can put a man on the Moon, why can't we build a better mouse trap?" This is not a valid question, any more than asking, "If birds can fly, why can't fish climb trees?"

Figure 3. NASA Budget, 1958-2005

Source. en.wikipedia.org/wiki/NASA_Budget

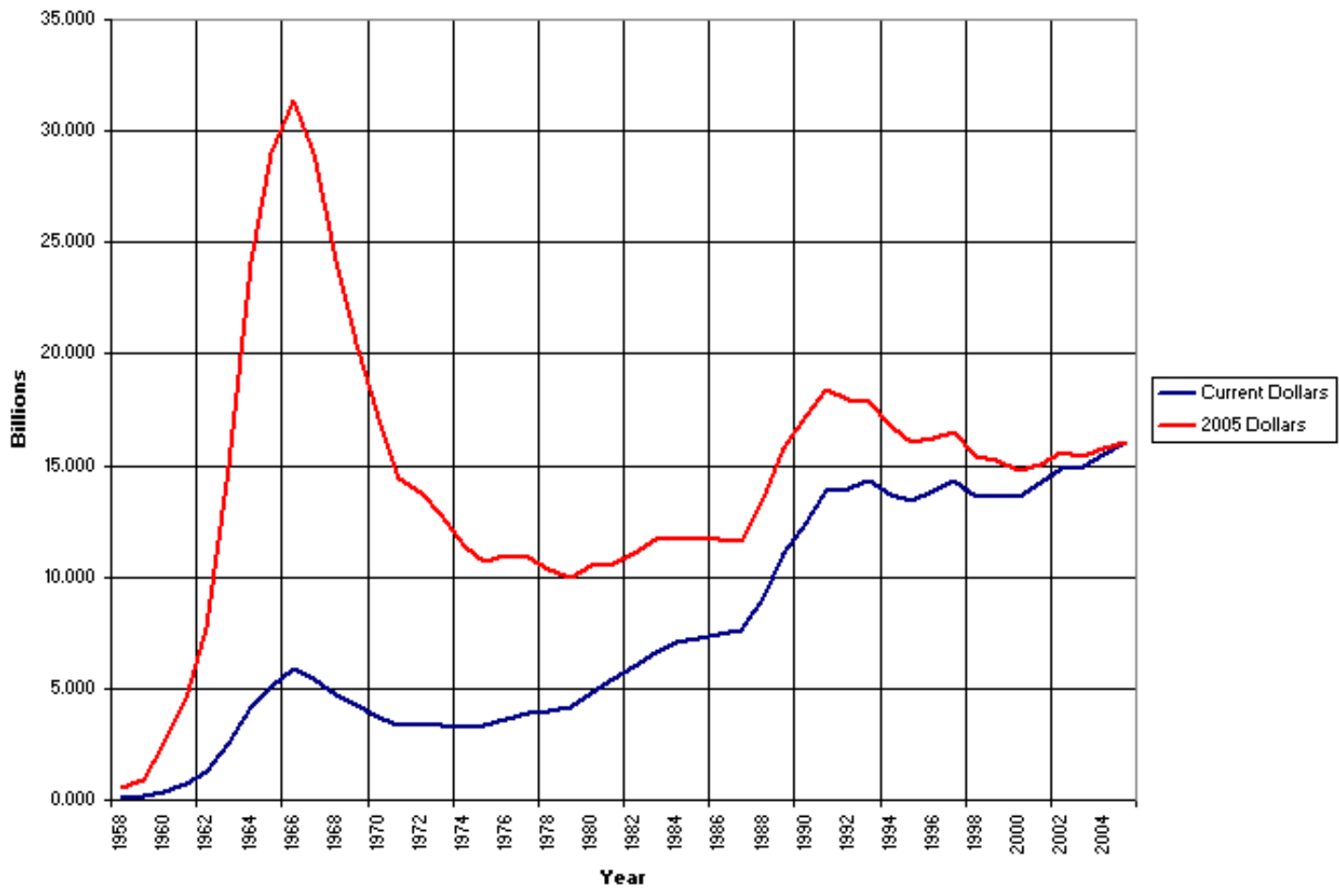

The Manhattan Project built the first nuclear reactor in 1942. Twenty years later, power companies were telling the public that nuclear power plants would make electricity so cheap that it would not be worth metering, and everyone would pay a flat monthly fee. Today-more than 60 years later-the US commercial nuclear power industry is struggling. Nolan and Lenski $(2006)^{13}$ wrote:

In pricing electrical power produced by these plants, no one had factored in the extremely high hidden costs of disposing of dangerous radioactive materials and of finally sealing off the power plants themselves.

The Vostok project put the first human in Earth orbit in 1961. Within five years, Stanley Kubrick was filming a motion picture that depicted Pan Am flights to a rotating Earth orbital space station and to the Moon. Today - more than 40 years later - no commercial effort has duplicated Yurij Gagarin's flight, nor is any likely to in the next decade. The flights of SpaceShipOne in 2004 reached the lower reaches of outer space for brief moments. They were space flights in a narrow technical sense, but they were not sustained space flights. It is one thing to accelerate to a speed of 3,800 kilometers per hour going straight up in order to peep above the atmosphere, but it is a far more difficult engineering problem to accelerate a vehicle to the $27,000 \mathrm{~km} / \mathrm{hr}$ necessary to achieve orbit, and as was 
tragically demonstrated by the disintegration of the Space Shuttle Columbia, to safely decelerate from that speed. Meanwhile, Pan Am is long gone, and there are no plans for a Ho Jo in the sky.

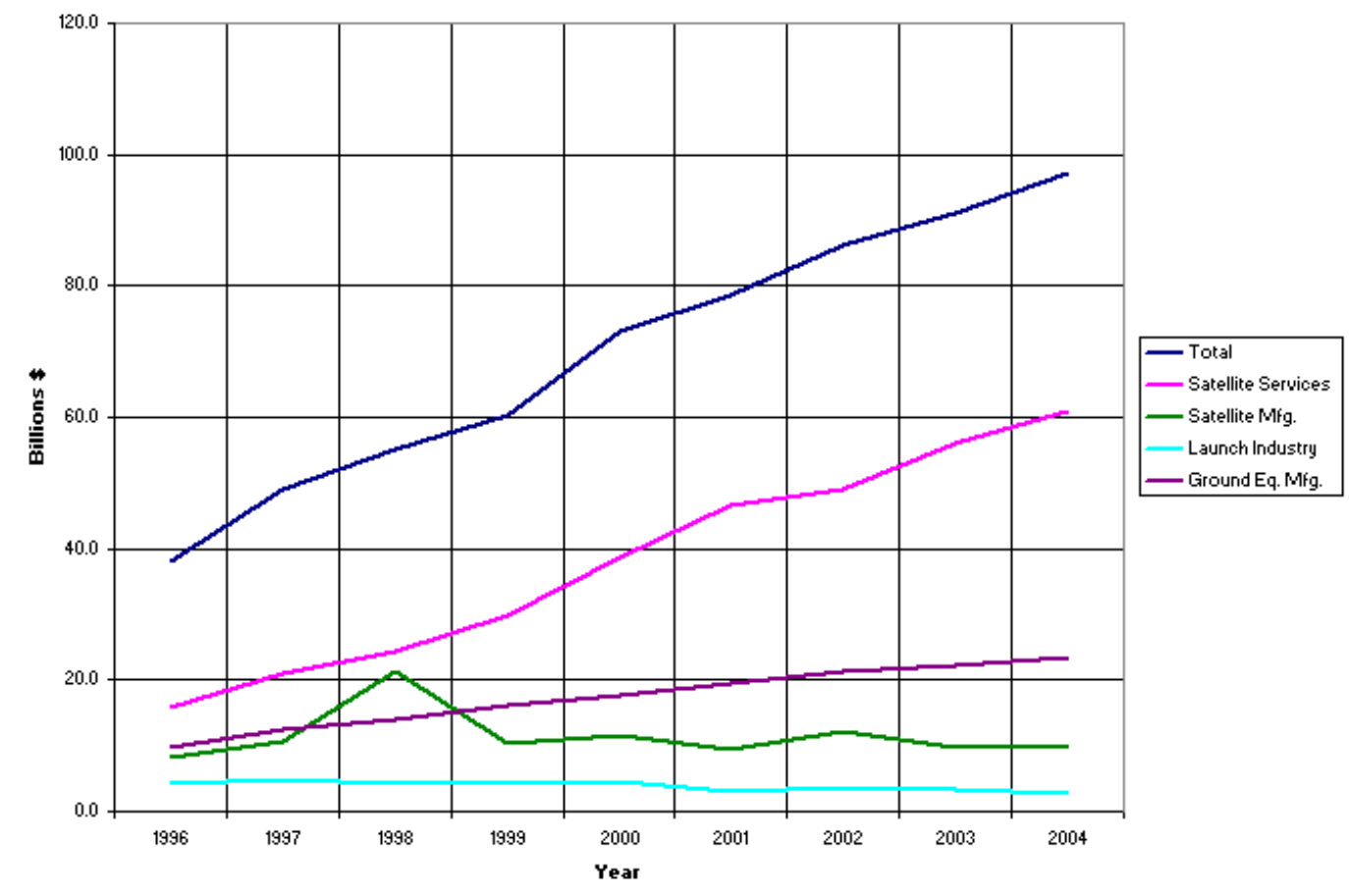

Figure 4. US Commercial Space Industry Revenue, 1996-2004

Source. www.sia.org/industry_overview/04industrystats.ppt

Clearly, technocracy is capable of outperforming technoeconomy in the short run, but its weakness is lack of sustainability. Technocracy can actually throw away capability after it has force-grown it at tremendous taxpayer expense. In the 1960, the United States government developed the Apollo manned lunar transportation system, the largest launch vehicle system (Saturn V, which suffered not a single failure in 13 launches), and the Nuclear Engine for Rocket Vehicle Applications (NERVA) upper stage for manned interplanetary missions, and within a few years abandoned all of them. These capabilities have yet to be duplicated. Since the "Apollo spike," advances in US government-sponsored civil space activities have been incremental. As a theoretical construct, the technocratic spike can be represented as a steep parabola (see Figure 5 below). The period of incremental activity following the spike can be represented as a linear trend. Technoeconomy, on the other hand, builds steadily, compounding its momentum, and can be represented as a geometric progression. One can speculate that in time, private-sector activities and capabilities could catch and surpass public-sector civil activities and capabilities... except that it is difficult to predict when the politically-motivated technocratic spike might occur. O'Donnell (1999) wrote ${ }^{\dagger \dagger t \dagger}$ :

The mass utilization of space resources for commercial and settlement purposes has not yet begun. There are no substantial technical barriers to living and working in space though cost is still a problem. Other problems are delaying our conquest of the final frontier: Space law and space policy problems.

\#†' O’Donnell, Declan J. 1999. "Property Rights and Space Resources Development." Internet. Available from http://www.mines.edu/research/srr/ODonnell.pdf; accessed 1 February 2005. 
Just because the technical capability to do something exists does not mean that it is a smart business proposition. Moscow, London, New York, San Francisco, and Tokyo all have subway systems, and "there are no substantial technical barriers" to building a subway linking one city to the other, "though cost is still a problem." Cost is hardly a trivial problem, especially in business. It is difficult to imagine what "law and policy problems" might be resolved to make a global subway project a reality. As engineers say, this class of problems is "in the noise level" compared to cost/benefit considerations.

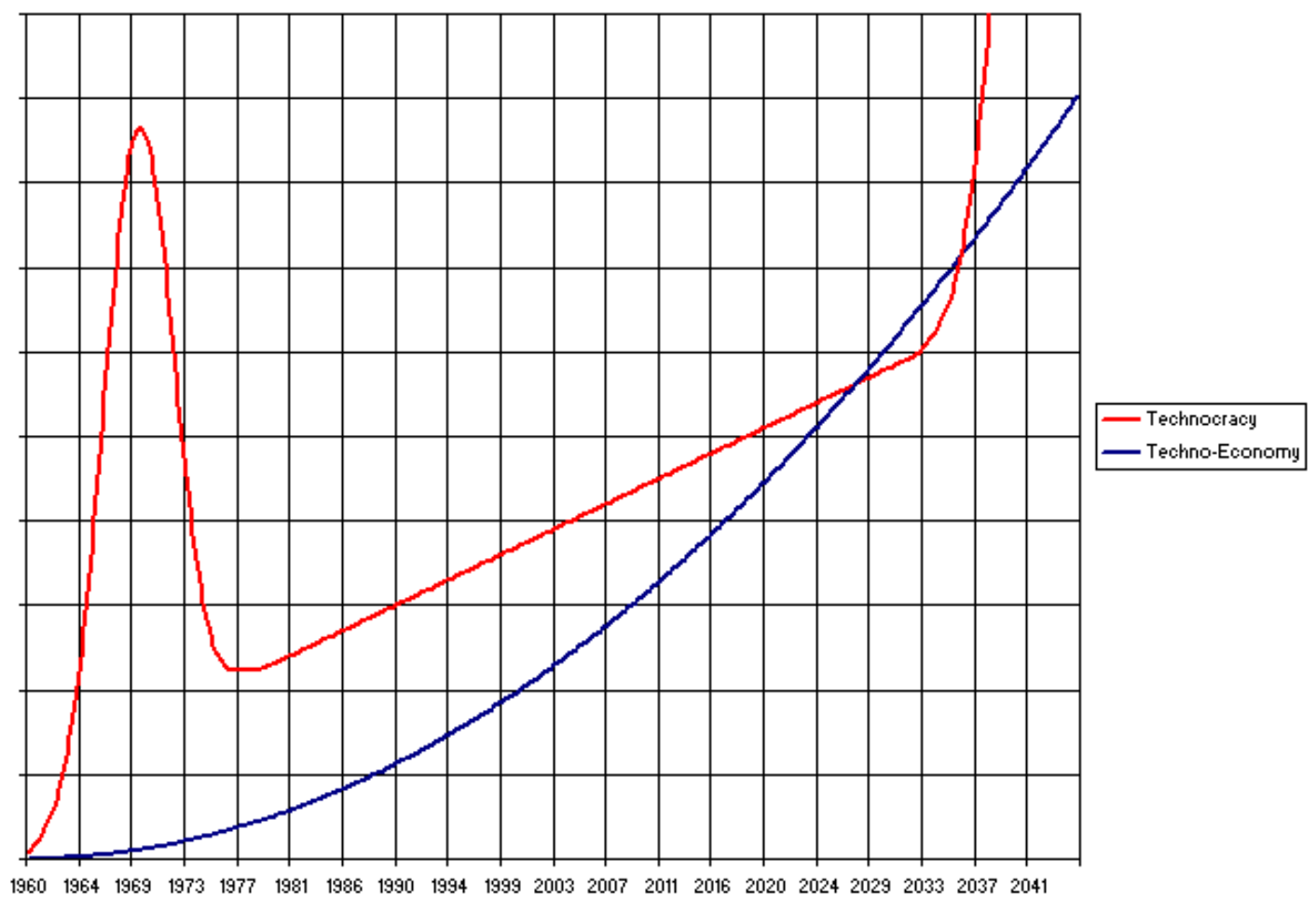

Figure 5: Technocracy and Technoeconomy in Space Development

The real barrier to commercializing space is the huge capital investment that is required to develop a transplanetary infrastructure. Libertarian space cowboys imagine that private enterprise can pull itself up to the Moon and Mars by its own bootstraps. These assertions ignore the history of opening frontiers.

In the early days of railroads, a private company might build a line from New York to Buffalo, but New York was already there, Buffalo was already there, and there were Albany and Schenectady in between. On the other hand, the transcontinental railroad that opened the West was a massive US government project to span a vast expanse of nothingness. Similarly, the Russian government built the trans-Siberian railroad.

A French joint-stock company went bankrupt beginning the Panama Canal; the US government stepped in and finished the job. The St. Lawrence Seaway was the joint project of two national governments.

The US government funded the interstate freeway system, which enabled a massive expansion of the automobile industry, trucking industry, the oil industry, and the suburbs.

The airline industry initially developed under federal contracts to transport mail. The Boeing B-707 was developed under an Air Force contract as the KC-135 tanker. The Lockheed L-1011 Tristar development project bankrupted not only Lockheed but Rolls-Royce as well, which was developing the jet engines for that airliner; the US and British governments stepped in to bail out these companies.

The commercial space launchers in service today were all originally developed on government contracts. Most of them began as ballistic missiles to deliver nuclear weapons to distant targets. 
Today, private companies build and operate trucks, ships, aircraft, launch vehicles, and satellites, but it is governments that maintain the highways, seaports, airports, and spaceports--the infrastructure that is the foundation of all of these commercial activities.

Developing infrastructure is a huge capital investment, while maintaining and operating it has a very low profit margin at best. This is something that government is better positioned to do than private enterprise. It has long been recognized that government has a legitimate role "to promote the general welfare" by providing the public goods that enable private goods to flourish.

The libertarian mantra that "government is the problem" is nonsensical. Neither is government the entire solution, but it is a necessary partner in the solution--on land and on sea, in the air and in space. Building a transplanetary infrastructure is not something that private enterprise is going to accomplish, except in the far future. First must come the political vision to build rainbow bridges to the heavens, then will come the economic incentive to travel them.

What makes libertarian rhetoric so seductive is that government seems to have dropped the ball. The Golden Age of Mercury, Gemini, and Apollo is long gone. During that time, anything seemed possible. It was anticipated that there would be a fully reusable launch system, a space station, a Moon base, and human expeditions to Mars, all by the early 1980s. The technology for all of this was either in hand or within reach, but there was no political necessity, and there certainly was no economic rationale. Clearly, if government were the problem, private enterprise failed to provide a solution. Private enterprise never built a space station or a Moon base, or sent humans to Mars. Is it likely to in the near future?

Government has been getting an increasingly bad rap in the space advocacy community since the end of the Apollo Era, but in truth the mad dash to the Moon was unsustainable, and measuring subsequent progress against the Apollo standard reflects unrealistically high expectations. Apollo was a Cold War anomaly that has not been repeated, and that may have no analog in the future.

Again, the central problem is infrastructure. When the Apollo program ended, it left some ground infrastructure (assembly and launch facilities later used by the Space Shuttle program) but no space infrastructure, and in that respect it was a developmental dead end. Political motivation for government to build lasting infrastructure is generated by private sector anticipation of colonizing a new human ecology in which it can produce profit. This is the common thread in all of the aforementioned government infrastructure projects. In contrast, no government has bothered to build a tunnel under the Bering Strait; there are no roads on either side, and so there is little prospect of a sustainable human ecology there. This is not to say that there will never be a Bering Tunnel, just not any time soon.

This may sound like a chicken-and-egg problem. Private enterprise is ill-positioned to develop infrastructure that it requires to thrive. Technocracy — government-directed technological development—has its limits, and may be politically motivated to develop capabilities that have little or no economic utility. A case in point is the depopulation of Siberia that has been occurring since the collapse of communism. The Soviet Union built infrastructure and forcibly moved population in a massive effort to colonize Siberia and extract its natural resources. Under a command economy, it was not clear that this was an uneconomical project, but as Russia has transitioned to a market economy, an increasing number of people have found that they cannot make a decent living in Siberia despite its vast natural wealth. There are enormous costs associated with extracting those resources in the extreme environment, and furthermore, there are considerable costs attached to transporting goods out of this remote region of the Earth to market. So, millions of Russians are abandoning the frontier to return to the bosom of Mother Russia's European heartland. Now, Siberia is paradise next door compared to the distant and forbidding Moon and Mars, yet here private enterprise is retreating from an ecology that government established. Private enterprise only recently duplicated Alan Shepard's 1961 suborbital flight. How credible is it that private enterprise is going to blaze trails to the planets in our lifetime?

It is about as credible as the hype about living on the Moon that Baby Boomers read in the Weekly Reader 40 years ago, or the grand vision of solar power satellite constellations 30 years ago, or a fleet of commercially owned and operated Space Shuttles 20 years ago, or the Iridium mobile telephone satellite constellation 10 years ago. It seems like every time you turn around, space endeavors are being oversold, whether they are governmental or commercial.

However, developing a spacefaring civilization is not an insoluble chicken-and-egg conundrum. It is more subtle than that, and there are solutions--not in all cases, but on the margins. Obviously, progress does occur, and while the pace of progress is not at a dead crawl, it does have constraints. The key conceptualization is of government and private enterprise in a push-pull relationship. When private interest becomes curious about what lies over the fiveyear return-on-investment horizon, it nudges government to stand straight and see further over that horizon. If the vista is promising, private interest encourages government to build the rainbow bridge to the pot of gold. Government then gets its piece of the action by taxing that pot of gold. 
The challenge is in recognizing that not every horizon hides a pot of gold, or if it does, it can be too costly to bring it home with the means at hand. Space technology is not a magic wand, and the High Frontier is not the Promised Land. Laissez-faire libertarianism is not the answer to space development any more than commandeconomy technocracy was; rather what is required is, as John Kenneth Galbraith prescribed for the United States half a century ago, a social balance between public goods and private goods (Sackrey et al. 2002). ${ }^{14}$ The concept of and need for sociopolitical balance between various economic power centers in society, including government, corporations, organized labor, international civil society, et cetera, is also described in Raymond Miller's Multicentric Organizational model of political economy (Miller 2000). ${ }^{\text {tth }}$ For space development to proceed and to succeed there must be a partnership between government and enterprise as well as among governments and enterprises, a transnational partnership of governmental and nongovernmental entities (Dudley-Rowley 2001, $\$ \$ \S$ Dudley-Rowley and Gangale 2006). ${ }^{15}$ It is not merely corporations or governments, but all sectors of human society, that must go into space.

The mini-entrepreneurs will certainly have a significant role in developing outer space along with the established aerospace companies. We need the best practices of both, and promoting an either-or dichotomy is misguided. The large picture is that developing outer space will take enormous sums of money and decades of effort, mostly on the taxpayers' dime, before there is enough "there there" to sustain commercial operations. The next big push into space, taking us back to the Moon and further outward to Mars, is therefore likely to be the result of a technocratic decision, as was the Cold War race to the Moon.

In the long run, such a technocratic model might play out as a transnational project on a fairly relaxed timeline, in the absence of a major problem to which a major, accelerated space effort can be seen in some light as a solution (Dudley-Rowley and Gangale 2006). ${ }^{16}$ In this case, although NASA is now planning its "return to the Moon as early as 2015 and no later than 2020 (White House 2004), ${ }^{, * * * * *}$ this could be stretched-out, and the program might also be down-scoped to the point that the path to sustained, profitable development of the Moon might be very lengthy, possibly not occurring until mid-century or even later.

\section{F. The Ramifications of Ending the Apollo Era}

However, all things are not equal, there are major problems that bear on all the world's societies, the solutions to which may lie in the science and technology of long-duration space exploration. These problems involve finding enough energy sources within the next few decades to run an increasing number of advanced industrial societies, guaranteeing the surviving and thriving of planetary population during an epochal climate change, and the offsetting of natural disasters that strike increasingly populated areas. These are "big science" projects. They are, in fact, bigger technical problems than getting a handful of people to the Moon and back on "flags and footprints" missions. However, sustaining long-duration exploration to Mars and building Moon bases, projects concerning off-planet locations where people can stay on a permanent basis, begin to approximate the level of difficulty and costs associated with developing alternative energy sources for global usability and offsetting epochal climate change and natural disasters in high-population areas.

But, the United States, in our contributions to meeting the challenges requiring "big science," sees us starting from a weak position. The political plug-pulling on the Apollo Era has had ramifications in terms of 1) lapse of America-to-the-Moon infrastructure/technology and 2) evaporation of Moon money to American Academe.

A History Channel series couches historical events in terms of Man, Moment, Machine. In terms of "man, moment, and machine," the rise of the Apollo program was a matter of moment and machine. But, its demise, along with the space shuttle and International Space Station that we are saddled with, was also a matter of "man." That man was President Richard Nixon.

In writing about John F. Kennedy's decision to send men to the Moon in May 1961, historian Roger D. Launius $(2000)^{17}$ argues that it is likely that Richard Nixon might have made the same decision had he won the election six months earlier; the flight of Yurij Gagarin aboard Vostok 1 would still have been a Soviet triumph, and the Bay of

†+\$Miller, Raymond. C. 2000. “Environmental Policy Implications of Clashing IPE Paradigms.” Internet. Available from

http://bss.sfsu.edu/ir/irjournal/WinterSpring01/DrRaymondMiller.pdf; accessed 3 July 2005.

$\S \S \S \S$ Dudley-Rowley, Marilyn. 2001. “The Globalization of Space.” Pacific Sociological Association Annual Conference, San Francisco, California, 30 March.

Internet. Available from http://www.ops-alaska.com/GlobalizationOfSpace/PacSoc.htm; accessed 3 July 2005.

${ }^{* * * * *}$ White House Office of the Press Secretary. 2004. "President Bush Announces New Vision for Space Exploration Program.” 14 January. Internet. Available from

http://www.whitehouse.gov/news/releases/2004/01/20040114-1.html; accessed 20 March 2006. 
Pigs invasion would probably have been an anti-Castro fiasco even with American air support. In the Moon decision, the machines were the rocket and the printed circuit board, and the moment was the Cold War, a month after the Bay of Pigs debacle; Launius doubts, that in this moment with these machines available, the man made much difference. The Apollo program was the child of the Cold War rivalry between the United States and the Soviet Union, and was specifically the child of the events of 1961. As Launius has described it, in May of that year the cosmic tumblers fell into place that enabled a decision to commit the nation "to achieving the goal, before this decade is out, of landing a man on the moon (Kennedy 1961)." "†tit The decision was primarily the product of sociopolitical forces and technology.

And, by 1970, the United States had already slammed the door on a sustained manned lunar exploration program by capping Saturn V production as 15 flight items (the last two were never even flown). Also dropped had been plans for an American manned landing on Mars in the early 1980s. By 1979, it had been seven years since Apollo 17, the last lunar expedition, and the last Saturn V launch vehicles were on static display for tourists. The Soviet Union had abandoned its L3 manned lunar landing program in 1972, and development of its N1 launch vehicle in 1974.

It is a popular historical myth that the United States turned from lunar exploration in order to devote more resources to the Viet Nam War. The fact is, the public diplomatic debacle of Viet Nam begged the successes of an American "win" in the race to the Moon. The US spent $\$ 500$ billion (in 2005 dollars) and 58,000 lives on Vietnam, not for fun and profit, but for power and prestige - largely prestige. For its trouble, it took a beating in terms of its prestige. For the US to have or to not have power over what President Lyndon Johnson called "a raggedy-ass little fourth-rate country" was relatively inconsequential; neither the American global strategic position, nor even the American strategic position in eastern Asia, was substantially weakened by the fall of the Indochinese dominoes. What really suffered throughout the 1970s as a result of the loss in Vietnam was American prestige. As it turned out, we could not "pay any price, bear any burden, meet any hardship, support any friend, oppose any foe, in order to assure the survival and the success of liberty (Kennedy 1961), ${ }^{,+1+1+}$ and bumping up against that bruising reality was a bitter blow to American pride. On the other hand, landing the first humans on the Moon was a sorely needed source of American prestige abroad, although it was a less-effective salve to the domestic American psyche. As the numbers show in Figure 6 below, canceling the US space program outright and giving all of NASA's budget to the Department of Defense would hardly have been noticed, either then or since. The historical fluctuations of defense spending dwarf the NASA budget, and they still do today.

Also, looking at only the funding history misses the programmatic details. The decline in the NASA budget starting in 1967 was due to the fact that the major capital investments in infrastructure (assembly facilities,

\#il Kennedy, John F. 1961. "Inaugural Address." 20 January. Internet. Available from http://www.jfklibrary.org/j012061.htm; accessed 3 January 2006.

\$+\$ Ibid 


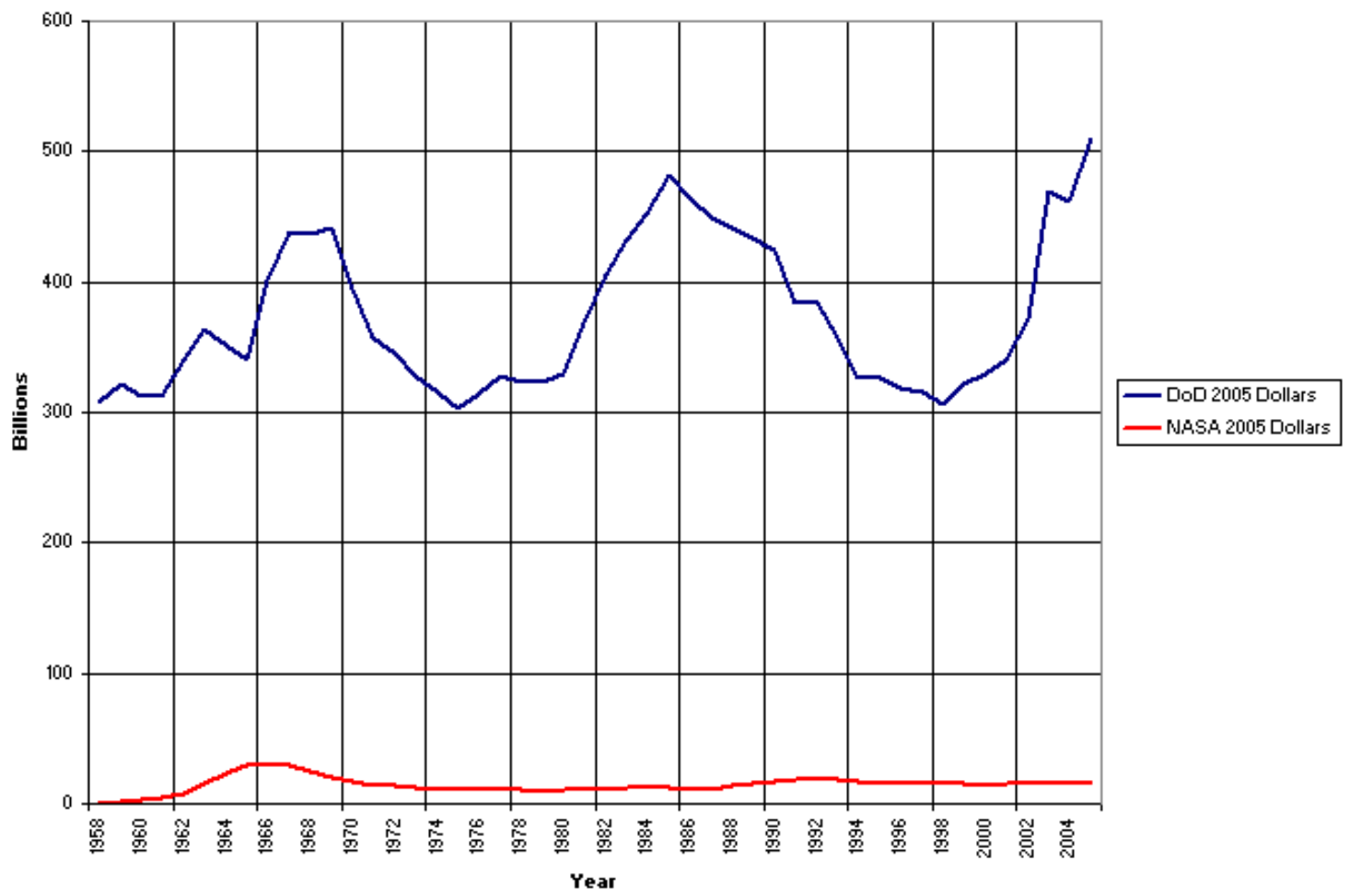

Figure 6: NASA and DoD Budgets, 1958-2005

Sources. sae.org

en.wikipedia.org/wiki/NASA_Budget

test chambers, transportation systems, launch pads, etc.) to support the Apollo program had been completed, as had most of the engineering design work for these ground support systems and flight systems. When one considers that from 1968 to 1972, the US flew 11 Apollo missions at a time when the NASA budget (which of course included funding for programs other than Apollo) averaged \$18 billion in 2005 dollars, compared to the peak budget in 1966 of $\$ 31.4$ billion in 2005 dollars, it becomes obvious that the US could have continued to explore the Moon indefinitely and relatively inexpensively. ${ }^{\S \S \S \S}$ That the US did not do this had nothing at all to do with the Vietnam War. The programmatic decisions affecting the lunar exploration program, specifically the cancellation of the last three Apollo missions, came in 1970, during the time when the American involvement in Vietnam was winding down. Lunar astronaut-turned-Congressman, Harrison Schmitt, refers to other programmatic decisions in 1972:

The momentum seemed to be for the United States to move forward with a continuous lunar exploration program and implicit in that is the potential exploitation of resources on the Moon in the foreseeable future, whereas in 1972 that all changed. The Nixon administration cancelled all those activities and it became obvious to the world that we would not do that (USS 1980, 54). ${ }^{18}$

In short, despite an ongoing war abroad, the US went to the great expense of building a railroad to the Moon that could have operated for many years and eventually supported profit-making enterprises, but instead it chose to tear up the tracks and scrap the rolling stock. But, this was a political decision, unrelated to treaties and wars. The truth was, at best, President Richard Nixon was ambivalent about continuing the exploration of the Moon. Yes, to some extent, it served to bolster America's global prestige, but it also served to keep the Kennedy mystique alive. The

$\$ \$ \S \S$ A reality of inflation: the 2005 NASA budget was $\$ 16$ billion, or about $90 \%$ of its average budget during the Moon mission years; yet this is considered a starvation budget that barely keeps the Space Shuttle and International Space Station alive. 
Apollo program ended without a follow-on program to continue the exploration of the Moon. If there were a man among the moment and machine, Nixon would stand out. It is an irony of history that the plaque on the Moon bears Richard Nixon's signature.

Courtesy of President Nixon, there were no clear national objectives to the American space program following Apollo. The Space Shuttle program emerged as a bureaucratic compromise between a NASA that had been sustained by Apollo funding and was frantically scrambling for some next grand development project that would be a new source of funding, a Department of Defense that had been itching for a piece of the human spaceflight action for more than a decade, and various other federal agencies that had space ambitions. The budgetary reality of the 1970s was that NASA would not be given the money to fund a large development project merely to keep humans flying in space for scientific and national prestige reasons.

The space shuttle system and the international space station are artifacts from this period. The two items began as part of the same package: a large space station that would be a center of research and manufacturing and a "workhorse" space shuttle to routinely ferry workers back and forth. However, the focus and sustained commitment seen on the Apollo project was not present, and so political, and therefore, budgetary considerations separated the two. The two items developed separately and unequally.

By the time the funding profile was developed, NASA and its partners knew there would be no immediate space station. It would be in the early 1980s before they would get full-scale development authorization on the space station. In the interim, they had tied a lot of other missions to the shuttle, which had the effect of altering the design of the shuttle. That had cascading effects in costs. A major rationale of the Space Shuttle developed as a transportation system to deploy and retrieve national security space assets, to extend the American Empire into nearEarth space, to seize the heights in order to command the ground below. This was its black ${ }^{* * * * *}$ justification. However, carrying spy satellites into orbit was not cost effective because that task had to be man-rated. And, a number of other design changes were made in order to launch this type of satellite. The size of the cargo bay had to be larger, dictated by the size of military next-generation reconnaissance satellites that tended to be placed into nearpolar, sun-synchronous orbits ${ }^{\dagger \dagger \dagger \dagger \dagger}$ from which they could surveil the entire planet. That mission required the capacity to launch out of Vandenberg Air Force Base in California and to be recovered there. That is why the shuttle has the specific type of wings that it does, so it can land at Vandenberg within one orbit from a sun-synchronous orbit (a near-polar orbit). When it launches out of Vandenberg, the shuttle heads south to a near-polar orbit. It flies over Antarctica and over the North Pole. To recover at Vandenberg is tricky. During the 90 minutes while the shuttle is in orbit, Vandenberg has rotated 1000 miles to the east. Once the shuttle enters the atmosphere, it uses its wings to go into a turn to catch up with Vandenberg. If not for the Vandenberg requirements, the shuttle did not need that cross-wing range capability.

Then, after all that consideration and expense, the Vandenberg requirements, in the end, turned out to be something of a dead issue. When OV-099 Challenger exploded in 1986 and the shuttle fleet was grounded for years on end, the American military realized that it could not count on the shuttle system for launch of its reconnaissance hardware. The space shuttle launch complex at Vandenberg Air Force Base was mothballed without ever having been used. ${ }^{\mathrm{tat}}$ Plans for enlarging the shuttle fleet with "blue" (i.e., Air Force owned) orbiters evaporated. National security satellites that had been specifically designed for the Space Shuttle, and that could not be reconfigured for other launch systems, flew on the first few missions when the shuttle fleet returned to flight in 1988. Since then, what started out as a substantially black program in a white wrapper has probably been mostly white, ironically emerging out of tragedy to become what the American taxpayer thought it had been all along.

\footnotetext{
${ }^{* * * * * *}$ Sensitive compartmented information (SCI), the most highly-classified national security programs; as opposed to non-SCI (white) programs.

$+1+i \dagger$ A sun-synchronous orbit is one that combines semimajor axis and inclination so that a spacecraft passes over any given point of Earth's surface at the same local solar time. The surface illumination angle will be nearly the same at every passage over that point. This consistent lighting is useful for satellites that image Earth's surface in visible or infrared wavelengths, such as meteorological, reconnaissance, and remote sensing satellites.

10t+ This was the second time Space Launch Complex 6 was mothballed. It was originally built to launch the Manned Orbiting Laboratory (KH-10), an Air Force reconnaissance platform based on NASA's Gemini spacecraft, which was canceled in 1969 in favor of the less-expensive, unmanned, film-returning spacecraft often referred to in open sources as Big Bird (KH-9). In the early 1980s, SLC-6 was reconfigured for Space Shuttle launches carrying, among other things, digital-imaging KH-12s. In the early 1990s, SLC-6 was reconfigured yet again, this time for Athena launch vehicles. Following only four Athena launches, SLC-6 is now being reconfigured to launch Delta IVs, making it perhaps the most expensive and least efficiently used real estate in history.
} 
The white justification for developing the Space Shuttle fleet was that it would serve to ferry crews and supplies to a space station. But according to this rationale from a programmatic standpoint, the transportation system and its destination should have been developed simultaneously. Without a space station, such a large, manned vehicle made little sense, at least in the white world, and the fact that such a space station did not even begin to be assembled until nearly 20 years after the Space Shuttle became operational points up the primacy of the Space Shuttle's black justification during its development.

Stuck with a large cargo bay as an artifact of this secondary mission, NASA later flew sortie missions of experimental pallets, some which contained habitable modules. For example, it outfitted the shuttle cargo bay with Spacelab modules (built by the European Space Agency [ESA]), which allowed some research to be done that might have been performed in a space station environment. Initially, the space shuttle system was supposed to reduce cost per pound to orbit by $90 \%$, and that point made it attractive as a space station ferry system. Now that there is a space station for the space shuttle to service, it is the most expensive ferry system ever built. It costs millions of dollars for every shuttle launch.

This is not to say that the United States has engaged in no space exploration whatsoever since the Apollo program, but simply no human space exploration. Even its robotic exploration of the Solar System has been anemic, and most of these accomplishments were due to the momentum of Kennedy's New Frontier. In the first 20 years of the space age, the United States sent missions to explore the Moon and every planet in the Solar System except the two outermost, Pluto and the recently discovered 10th planet, 2003 UB313. . $^{\S \S \$ \S}$ The unmanned explorations of Mars that have given us so much information about that planet of late owe their existence to New Frontier impetus.

The Nixon Administration did more than end the Apollo program that would have laid the groundwork for "big science" answers to long-duration space exploration and also to alternative energy sources, epochal climate change offset, and disaster mitigation. People don't miss what they don't remember what they once had. And, they won't see what "might have been" if they don't know how to do that. Stepping back from the Moon and beyond was nothing short of a retreat into ignorance.

The decisions of the Nixon Administration "dumbed down" American postsecondary education as a consequence of the lapse of the Apollo program and the follow-on science and technology events that did not happen in the 1980s and 1990s. The Apollo Era stimulated knowledge production and technological advancement because the federal government poured money into colleges and universities to grease the engines of prestige on the America-to-the-Moon front. Over the course of time, the American postsecondary student body swelled owing to new demographic realities and changes in the economic profile of the United States that were in part owing to the changes wrought by Apollo Era technological advancements and forward thinking. An increasing number of women and minorities gained access to colleges and universities, as well as those who might otherwise have pursued careers in manufacturing. As a result, when Apollo-driven federal money (and oversight) disappeared from Academe, the impact was greater than if America had never gone to the Moon. Postsecondary administrators free-reined a new kind of governance called the "corporate model" to manage the loss. In the absence of federal funds, academic administrators increasingly raised student tuitions and invented creative ways to teach whole new armies of students with professors on starvation wages.

The latent dysfunction of this corporate model is that it has robbed funds and resources from academic faculties and has created a new and dangerous profile for the American brain trust. The plurality of postsecondary teachers in the United States is without adequate salaries, benefits, and resources in the national aggregate. A 2003 figure generated by the American Association of University Professors put it at $65 \%{ }^{* * * * * * *}$ On top of that, the very name of "professor" is denied two-thirds of America's college and university teachers. They are called variously: adjuncts, instructors, temps, contingent-hires, and part-timers. When university administrators can get away with it, to get "more bang for their buck," they pay graduate students and upper-level undergraduates even worse starvation wages to teach college students. What began as a kind of emergency measure in the post-Apollo years has become a way of using postsecondary funds for other things than teaching America's students, like constructing "legacy" buildings on campuses. The already rigid feudal and military-like ranking system of tenured assistant, associate, and full professors have been made more rigid with a division between small have and large have-not sectors, those who can access the ranking system and those who don't have a prayer - not because the latter are "bad professor" material, but because of the sheer structural violence of the situation.

$\S \S \S \S \S$ NASA launched the first mission to Pluto, New Horizons, on 19 January 2006.

${ }^{* * * * * * *}$ That figure likely rises higher in the national aggregate from one semester/term to the next because of the usage of semester/term contracts and the shifting needs of colleges and universities from one semester/term to the next. 
The 2005-convened Commission for the Future of Higher Education within the U.S. Department of Education wrongly laid the blame at the feet of faculty, claiming that professors spend more time on research than on inventing innovative new teaching techniques (http://www.aaup.org/AAUP/issuesed/comm/). This "finding" is less of a finding than a regurgitation of an anecdotally-based ultra-conservative theme in journalist Charles J. Sykes' 1989 book, ProfScam:Professors and the Demise of Higher Education. ${ }^{19}$ In return, the American Association of University Professors complains "Excessive use of, and inadequate compensation and professional support for, such contingent faculty exploits these colleagues and undermines academic freedom, academic quality, and professional standards (http://www.aaup.org/AAUP/issuesed/contingent/)." That is a much-too-polite way of saying that twothirds of the American brain trust is being robbed of job security, adequate wages, access to offices, laboratories, and libraries. The AAUP has not yet painted the picture concerning what kind of damage that is doing so that the public and politicians can understand it.

To put it in plain-speak, post-Apollo academic practices are "killing the goose that lays the golden eggs." The American postsecondary education system is the place where deficiencies in poor K-12 training is remediated. It reproduces the American knowledge base (that goes on to benefit the world and our place in it). It creates "firstround" innovation in American science, technology, and values. The venues that receive postsecondary graduates for-profit companies, non-profit organizations, government laboratories, etc. - are "second-round" innovators that expect to be continuously fed by Academe. Thirty-plus years of the post-Apollo corporate model of American Academe has been the thing that has "dumbed down" postsecondary education, not professors focusing too much on research rather than their teaching. If anything, Academe can't hire up every sufficiently credentialed scholar, scientist, and engineer fast enough to do all the research that they can and also to teach, and the federal government can't step in quickly enough with the funds, resources, and oversight to make sure that these academicians are secure in their livings and have adequate access to resources to do their jobs. ${ }^{\dagger \dagger \dagger \dagger \dagger}$ That is because the basis of humanity's highest form of civilization (the advanced industrial subsistence modality) is threatened as the fuel that makes it run is running out. At the same time, the waters are rising from global warming and many indirect effects are expected. This is not just a short-term inconvenience, but epochal change that will impact us hard in ways that Pleistocene supervolcanoes and the onset of the Holocene Epoch did. Or, like asteroid strikes did for species on Earth which preceded us. The responses to these challenges will come from insights that can only derive from a humanity that extends itself into new frontiers, which comes up with workable new ideas that derive from the crosspollination across multiple disciplines pondering the problems.

However, the authors seriously wonder if there is enough brain power left in a "dumbed down" and demoralized American Academe at present to engage the great science projects that face humanity. An increasing number of graduate students from abroad who used to stay in the United States to employ their expertise after their graduate studies at American universities are going back home to India, China, and other countries where they can make good livings and where the standards of living are increasing. In the meantime, American unemployment is rising and its standard of living is falling.

Academe has typically been a "black box" for politicians who have allowed colleges and universities to govern themselves without too much oversight. But, if policymakers do not start looking at Academe as the most important industry in the United States and penetrate the corporate veil that a few thousand top postsecondary administrators have erected around their activities, then America will not lead in the contributions to the "big science" problems of the world. Those who solve those problems will lead the world system of societies.

\section{G. Producing One-of-a-Kind "Big Science" Technologies}

If the United States hopes to lead in a world system of societies solving for "big science" problems, it must secure its reserve army of first-round innovation knowledge workers feeding on the scraps of a post-Apollo postsecondary education system. Scraps that are parceled out by top-rung university administrators like Somali warlords doling out United Nations food rations. Once this army of scholars, scientists, and engineers are secured, then their production will have to be integrated into the advanced systems projects that will address the needs of a planet and its people in peril.

$\mathrm{HTH \dagger \dagger}$ It will take major federal oversight to end wide-scale age discrimination in Academe that is practiced to hire less costly, less expertise-laden "junior" professors into most academic positions, and that admits mostly young people into doctoral programs who are less experienced and who are less trouble for elite tenured professors to mold into their own images. These discriminatory practices keep those scholars, scientists, and engineers with two- and three-generation-depth expertise levels from passing on their knowledge to young people and enhancing academic environments. Many wheels are reinvented in this way. 
The authors' discussion (above) of the political-economic aspects of human spaceflight also demonstrated that making its hardware and systems is not like making desktop computers. It will be the same for the hardware and systems required to find energy alternatives to drive an advanced world system of societies and to respond to global warming and natural disasters in ever-increasingly populated areas.

Following his experiences with military projects and the Apollo program, John de S. Coutinho (1977) ${ }^{20} \mathrm{a}$ visionary design engineer, came up with management principles to minimize the risk of creating advanced systems projects by focusing on the entire development cycle of those projects.

The aerospace sector is a unique context borne of its history, traditions, and products. Because of all of this, it has developed a set of objectives that are uniquely characteristic of it and which are relatively uniform throughout the industry. Its projects are typically first developed for military use, under government contract, and only after the projects have demonstrated their merits in military service or under government sponsorship are they adapted for commercial use. Commercial operators usually cannot assume the financial risks involved in introducing advanced products into commercial service, except on a very limited basis. Military forces, on the other hand, respond to a different environment, one of potential threat; it cannot afford to lag technically and must strive constantly for the most advanced weapon systems since the security of nations are at stake. How like the demands of "big science" projects where the threat of bellicosity from a human enemy is replaced by the ferocity and/or extremity of the environment.

Advanced systems projects are the heart of our technical progress, Coutinho asserted, and one of the greatest impacts on human societies has been the capability to convert technical advances into combined functional systems. Within this context, the aerospace industry, and only the aerospace industry, has demonstrated a remarkable, continuing capability for incorporating new technical advances in its products (Coutinho, p. 400).

Coutinho offered a thumbnail history of advanced systems projects (1977: vii):

The concept of advanced systems was born in the military shortly after World War II when it became necessary to integrate advanced electronics, computers, power operated flight control systems, jet engines, airframes, "integrated logistic support", specially trained air crews and maintenance personnel, all into an efficient, "cost-effective," workable "system." This "systems engineering" technology which has come to include...man in the loop, was developed in bits and pieces over time by the military and eventually evolved at an unprecedented rate....

So, advanced systems projects have existed only since World War II, and they have focused on three related areas:

- The development of major military systems

- The application of atomic energy

- The space program

Converting technical advances into combined functional systems produced results of incredible magnitude and effectiveness; but entailed dramatic increases in costs. Investments totaling billions of dollars are often required. The design, development, and deployment of these systems take considerable time - years on end. And, finally, the risks associated with such systems-development projects are high (p. 7). In this, they are not like the typical project being developed in the commercial sector. Likewise, the management techniques for the development, acquisitions, and assurance (including safety) of advanced systems are not like the procedures for procurement of existing commercial products, services, or systems which are offered for sale on a competitive basis in the public market (p. 8). One cannot simply go into a market, point to an existing advanced systems item, and demand that a salesperson deliver it on a particular date. Moreover, the advanced systems worker is not like the non-creative worker in a strictly commercial organization. The former works in a team of creative technical specialists. They do not respond to the same controls and motivational forces that contain and drive other workers (p.8). The workers of advanced systems projects produced Apollo and the several generations of Russian space stations, driven by motives other than just their paychecks.

The basis of managing an advanced systems project is to understand its development cycle, beginning with the recognition for the need of new systems, their technical definitions, their source selection, their contracting development, their qualification, their acceptance, their operational testing, and their release for production, as 
applicable to the type of the system (Coutinho, p. viii). The process requires the establishment of an empirical database, the construction of applicable models, establishing formal requirements, monitoring the design process to assure that the system will comply with the requirements, and demonstrating that the system conforms with the requirements (p. 2).

Very little charting out has been done of the development cycles of responses to sea level rise and other global warming effects, of responses to disasters in increasingly populated areas, and of alternative energy sources that can drive societies at the level that petroleum does. Perhaps the best charted out "big science" project is manned space projects, that has a history connecting to advanced systems management, although the development cycle of longduration space exploration still is lacking in many regards.

The advanced systems management procedures that Coutinho derived from the military aerospace industry "formula" was as follow (p. 403).

The overall systems development process is broken down into individual functions, with each function acting as a component of a feedback loop. This results in a complex system of loops operating on various levels, with many lesser loops within the higher-level loops. Deficiencies in the output of any loop are cycled back into the input, and the feedback cycles continue until each deficiency is corrected. In all significant functions, the feedback loop goes through the customer's and/or regulator's technical monitoring organizations.

In particular, deficiencies observed during demonstration testing or service monitoring are fed back, often through various research cycles, to improve the technical requirements. These in turn control the design, development, and production processes. In this process there is a constant, decentralized improvement cycle taking place in each loop.

Improvements are being made continuously in iterative steps, usually in small increments. Spectacular advances such as the introduction of the jet engine or of electronics are rare; nevertheless such advances are much more likely to occur in an environment of continuous progress where everyone is in search of new solutions and where there are few pressures to retain traditional, frozen design concepts. The great overall technical advances in aerospace products rest on the sound base of a steady, continuous effort in an iterative process to achieve small incremental improvements over a wide range of functions.

\section{H. Time Is Running Out}

So, a tried and true formula on how to proceed is available, but time is running out to solve for "big science" problems and the fewer wheels that have to be reinvented the better off we are. The authors have made a calculation based on known oil reserves, national populations, and consumption rates. According to these figures, we have about 29 years remaining to make a conversion to alternate power sources -- if the United States can bring its oil consumption down to the Japanese rate and if Asian societies rise to the Japanese rate (Table 2 below). 


\begin{tabular}{|c|c|c|c|c|c|c|}
\hline & & & & Per Diem & Per Annum & $\begin{array}{l}\text { Per Cap } \\
\text { Per Ann }\end{array}$ \\
\hline & & & Pop & $\begin{array}{l}\text { Cons } \\
\text { (Mbbls) }\end{array}$ & $\begin{array}{l}\text { Cons } \\
\text { (Gbbls) }\end{array}$ & $\begin{array}{l}\text { Cons } \\
\text { (bbls) }\end{array}$ \\
\hline & 113.8 & US & 301139947 & 19.60 & 7.15 & 23.76 \\
\hline & 733.9 & China & 1321851888 & 6.53 & 2.38 & \\
\hline & 207.6 & India & 1129866154 & 2.45 & 0.89 & \\
\hline & 401.1 & S Korea & 49044790 & 2.15 & 0.78 & \\
\hline & 17.3 & Hong Kong & 6980412 & 0.29 & 0.10 & \\
\hline & 121.9 & Singapore & 4553009 & 0.80 & 0.29 & \\
\hline & 39.8 & $\mathrm{CH}+\mathrm{IN}+$ Tigers & 2512296253 & 12.22 & & \\
\hline \multicolumn{7}{|c|}{ World Oil } \\
\hline \multirow[t]{7}{*}{ Reserves } & 1635.4 & EU & 490426060 & 14.68 & 5.36 & 10.93 \\
\hline & & Japan & 127433494 & 5.578 & 2.04 & 15.98 \\
\hline & & US at Japan Rate & 301139947 & 13.18 & 4.81 & 15.98 \\
\hline & & Asia at Japan Rate & & 109.97 & & \\
\hline & & World & 6602224175 & 82.59 & 30.15 & \\
\hline & & World w/Asia\&Us & pan Level & 173.92 & 63.48 & \\
\hline & & Avg & & 128.26 & 46.81 & \\
\hline $\begin{array}{l}\text { Years to } \\
\text { depletion }\end{array}$ & 29.38 & Pop Incr Adj & & & 55.67 & \\
\hline
\end{tabular}

\section{Table 2}

https://www.cia.gov/library/publications/the-world-factbook/

http://www.un.org/esa/population/publications/longrange2/WorldPop2300final.pdf

As the oil is running out, the waters are rising and the effects are visible, with socioeconomic impacts attached. Lohachara Island, in India's part of the Sundarbans where the Ganges and the Brahmaputra rivers empty into the Bay of Bengal, was reported in December 2006 to be permanently swamped by the sea owing to global warming effects. It is one of a number of several "vanishing islands" in India's part of this delta area that in the past two decades have been permanently flooded and that have left 6,000 families homeless. rise, they will cover whole island nations, from the Maldives to the Marshall Islands, inundate vast areas of countries from Bangladesh to Egypt, and submerge parts of coastal cities around the world. In all, a dozen islands, home to 70,000 people, are in danger of being submerged by the rising seas. ${ }^{\$ \S \S \S \S \S}$ Already, in Bangladesh, farmers near the Bay of Bengal, who once grew rice are now raising shrimp because of the encroaching sea. One of the effects of global warming is to worsen storms. As weather warms, Bangladesh is likely to face increasingly violent storms. Surging seas will carry saltwater increasingly further up the country's rivers, ruining soils. ${ }^{* * * * * * * *}$ In the United States, 200 villages in Alaska are fighting for survival. Three, including the town of Kivalina, may be lost within the next decade. Less ice along the Arctic coastline owing to global warming means less protection from winter storms that undermine the coastal areas where towns are located. In addition, Arctic coastal dwellers depend on hunting and fishing for subsistence and fish and game stocks are being affected by global warming. Inland in the subarctic, millions of acres of Alaskan forests have been wiped out because warmer winters allowed for larger populations of spruce beetles and other insects to kill the trees. ${ }^{1+t^{\dagger} \dagger \dagger}$

No amount of Halliburtons can hold back the sea or ameliorate the other things. These are root, human survivallevel, problems that require brainpower, not bulldozers to solve. Returning to the Moon, beginning with those first tentative steps to place a permanent human presence in the solar system, will help us with those larger problems.

+1+t+t http://en.wikipedia.org/wiki/Lohachara_Island

$\S \S \S \S \S \S \S \mathrm{http}: / /$ whyfiles.org/259melting_ice/\# (3 May 2007)

******** http://www.Sun-Sentinel.com (3 May 2007)

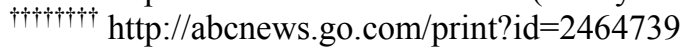


Returning to the Moon, this time to leave infrastructure, steps to the "big science" project of extending the human ecology off the planet and to live in the different world that this one is becoming. The knowledge we gain from learning to live in the extremest of environments will help us live on an Earth made more extreme - and perchance to make it more livable than it ever was with quality of life for all. The vantage point of envisioning the Earth from above it has always benefited humankind and will continue to do so. But, getting off the Earth and learning to survive out there will teach us whole new lessons about what it means to be both human and humane.

\section{Results - The Extension of Ideas}

\section{Looking Ahead At the World System of Societies in Space}

Our experience working with other national partners on the ISS has taught us that space did not have to be about national demonstrations of technology as once they used to be in order to make progress in space. The requirements of partnering has introduced us to:

- Very unique engineering solutions ironically engendered by tight budgets of national space programs and hard economic times in their host societies; and

- The invention of new social forms engendered by the unprecedented level of international cooperation required for solving the problems of human duration in space.

The United States is likely to continue to partner with other liberal democracies on major space projects, but will probably be reluctant to do so with China because of technology transfer concerns, especially if China's geopolitical goals remain uncertain. Evidence in favor of this conclusion is that the United States invited post-Soviet Russia to partner with it, Europe, Japan, and Canada on the International Space Station; China was not invited, and it is making plans to assemble its own space station beginning in 2012. Extending such a geopolitical rivalry into space might be fairly benign, as was the Space Race of the 1960s.

The United States has not needed to outdo anyone since the Apollo missions to the Moon. Even the Soviet copy of the Space Shuttle, the Buran program, was canceled in 1993 before the first manned flight. $1+1+1 t+$ In space, at least, the US is a satisfied nation-state, the consummate "lion" in Randall Schweller's zoological description of nation-states:

Lions are states that will pay high costs to protect what they possess but only a small price to increase what they value.... As extremely satisfied states, they are likely to be status-quo powers of the first rank (Schweller 1994, 101). ${ }^{21}$

Unsurprisingly, what we have seen from the United States since the development of the Space Shuttle in the 1970s is status quo behavior in space. Moreover, the scrapping of the Saturn V launch vehicle and the NERVA upper stage has been likened to the decommissioning of the Chinese Navy in the 15th century. The Ming government had the capability to launch an age of exploration nearly a century ahead of Europe, yet stepped back from this adventure. China was a lion, a satisfied power. In the centuries that followed, it declined and was overrun by foreign powers.

Do not count on China making the mistake of missing out on the next great age of discovery. In the mid-20th century China recovered its independence, and has been a rising power ever since. At the turn of the 21 st century it is hardly a satisfied power. It is poised to become the East Asian hegemon, has irredentist claims on Taiwan as well as other territorial claims. In Schweller's menagerie, China may be a jackal:

Jackals are states that will pay high costs to defend their possessions but even greater costs to extend their values (Schweller 1994).

Or, perhaps, China defies Schweller's zoological categories and is a unique animal... the dragon? However, the American Century is behind us. China became space-launching state in 1970 barely a decade after the Soviet Union and the United States. For several decades its space activities were constrained by its underdeveloped economy, however, estimates are that China's gross domestic product (GDP) will surpass that of the United States in 30 to 40

+t+t+! The only unmanned flight of the program occurred on 15 November 1988. 
years (Pesek 2005). ${ }^{\S \S \S \S \$ \S \S \S}$ Meanwhile, its developing manned space program has caused barely a stir in the U.S. Reportage of its first mission, Shenzhou 5, piloted by Yáng Lìwěi on 15-16 October 2003, shrugged it off as repeating something the Soviet Union and the United States had accomplished four decades earlier. This is far off the mark. The Shenzhou design is based, not on mid-20th century, but on turn of the 21 st century, technology. It appears to be more versatile than the Soyuz spacecraft that the Soviet Union/Russia has flown for four decades, and it remains to be seen how the Orion (formerly called the Crew Exploration Vehicle), with which NASA plans to replace the Space Shuttle, will measure up. The orbital module at the front of the Shenzhou is reported to be capable of being connected to others as building blocks for a small orbital station or as add-on modules to a larger station (Jones 2006). ${ }^{* * * * * * * *}$ China is also reported to be interested in lunar and Mars exploration (McDonald 2003). ${ }^{\dagger \dagger \dagger \dagger \dagger \dagger \dagger}$

The Chinese "are advancing whether or not the U.S. or others are teaming with them," Vincent Sabathier, Senior Fellow and Director of Space Initiatives at the Center for Strategic and International Studies (CSIS, Washington,

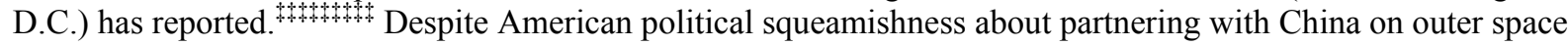
production, NASA Administrator Michael Griffin went to China in late September 2006. Sabathier commented on the rationale of the visit, outlining several points:

- The rest of the world is cooperating in space with China

- China has more than 50 projects in space cooperation with Russia alone

- China can latch up to the International Space Station because of a ready and willing docking port on the Russian segment of the station (the APAS-89 docking adapter)

- The gap between the end of space shuttle flights and takeoffs of the, as yet, unbuilt Crew Exploration Vehicle (Orion) might be filled by Shenzhou spacecraft rather than rely solely on the Russians

Being standoffish concerning cooperation with China on outer space production, while understandable, is likely not the best sector to play hardball with that country concerning geopolitical issues and other concerns like human rights. That is because Russia and Europe will not discontinue their space collaborations with China, and for the United States to hang back cannot be in our best interests. A latent function of such partnerships, which directly address human progress, is that they are avenues through which liberal pacific democracies can express their concerns to China.

\section{J. Immediate Contributions of the Return-to-the-Moon}

The two most immediate contributions of a Return-to-the-Moon are:

1) The establishment of proper advanced systems development management principles ${ }^{\S \S \S \S \S \S \S \S}$ such as that which characterized the development of Apollo program hardware, software, and systems, and that can be expected to exceed the Apollo model, without which the mitigations and solutions concerning "big science" projects, such as alternate power sources and global warming cannot be attained ${ }^{* * * * * * * * * *}$

2) Increasing confidence and pride of those nations that engage in Return-to-the-Moon projects, an important intangible considering the hard times ahead

$\S \S \S \S \S \S \S \S$ Pesek, William Jr. 2005. “China Is Neither Japan Nor the Soviet Union. Bloomberg.com, October 13.

Internet. Available from

http://www.bloomberg.com/apps/news?pid=10000039\&sid=asQZkFCRv55I\&refer=columnist_pesek; accessed 16 March 2006.

Jones, Morris. 2006. “China Might Be Planning Early Space Station Attempt.” Space Daily, 19 February. Internet. Available from http://www.spacedaily.com/reports/China_Might_Be_Planning_Early_Space_Station_Attempt.html; accessed 16 March 2005.

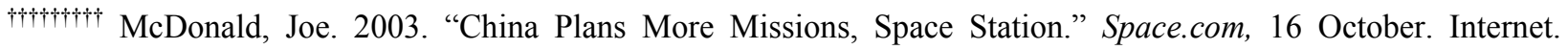
Available from http://www.space.com/missionlaunches/china_plans_031016.html; accessed 16 March 2006.

tottlt http://www.space.com/news/060813_griffin_china.html "Griffin to Go to China: But What Will He Accomplish When He Gets There?" by Leonard David

$\$ \$ \$ \S \$ \$ \$ \S$ As described by John de S. Coutinho Advanced Systems Development Management, 1977.

See "The Architecture of Time, Part 3: Project Management in Two-Dimensional Time," by Thomas Gangale, AIAA Space 2007 Meeting. 
The "Orion Era" poses an opportunity to further develop advanced systems management principles that will come to characterize "big science" projects. An example of such innovative project management tools is the time map, a format for displaying two-dimensional time. The Gantt chart depicts the current prediction of how the future is going to unfold, but it does not adequately tell the history of the project's efforts to get to that future. This is because the Gantt chart is really a series of charts, each of which has only one dimension - time - running from left to right across the page. The vertical dimension does not signify a continuum, but is simply a means of compiling the schedule of individual albeit interdependent milestones onto one visual display. It is today's snapshot of how those milestones relate to each other in the overall schedule, but it does not show very well how those milestones have influenced each other over time. It would be valuable to have some way of displaying all of yesterday's schedule snapshots as well as today's on a single chart. Then one could see at a glance the nature of the trends for each milestone and how they feed into the trend of the master schedule. This can be done by reformatting the chart so that a second dimension of time is displayed. The time axis on a conventional schedule chart isn't real time in the sense of showing the occurrence of actual events with respect to the passage of time; it is only projected time - the pseudo-temporal axis along which a manager positions his best guesses of when he will achieve his milestones. In a chart that not only contains the pseudo-temporal axis but also a second axis corresponding to the actual passage of time, one can see the history of a program's perception of the future - how schedules have been influenced by the course of events, and how they have evolved with time. Presentation of schedules in this new two-dimensional format provides managers an extra dimension of information, enabling them to make better subjective judgments on how realistic the current schedule is, and how it may change in the face of possible future events (Gangale 2007). ${ }^{22}$

The ability to do "big science" is all about the future of humanity. People need hope in the face of worsening weather, loss of national coastlines and homes, scarcity of oil and all the things that the loss of oil means. Kenneth S. Deffeyes $(2005$, p. 8$){ }^{23}$ a Princeton geology professor familiar with the petroleum industry, has outlined a constellation of impacts that those of us in advanced industrial societies can expect in the near future:

- Down-scoping of personal and family automobiles (i.e., trading in SUVs and luxury automobiles for more economic vehicles, like high-efficiency diesel and hybrid cars)

- A re-acquaintance with local produce and varietal presence/absence according to season

- A diminishment of agriculture that depends on diesel fuel and mineral fertilizers

Those societies reliant upon imports of agricultural products heavily dependent upon petroleum resources would suffer the most. He foresees the beginning of mass starvation in the Third World.

- An upswing in mass transportation usage, of relocation to jobs closer to workers' homes, and teleconferencing

- Agonizing over alternative energy sources: nuclear and coal plants and technologies that use more energy than they produce

- Scrambling for high-efficiency diesel engines, for wind farms, and for undeveloped hydroelectric sites

Not discussed in Deffeyes' list was the re-emergence of the all-electric car for close-to-home commutes. He did mention the possibility of the natural gas-powered car, which would be feasible for American use if we could free up our surplus natural gas from electrical power generation by converting to more nuclear and coal power plants (pp. 58-59). Rapid airplane travel, a hallmark of our current level of globalized world, will see airline engine manufacturers attempting to improve their compression ratios to obtain greater efficiencies and mounting them on existing airframes (pp. 185-186). The upshot of Deffeyes' list is, people worldwide are, or soon will be, noticing that the supply of oil is becoming short.

Deffeyes argues that we don't have time for an investment in research and development for energy alternatives because we ignored the earlier warnings about a global oil peak (p. 182). We also ignored warnings about global warming, too.

Ironically, several states of emergency converging on the world system of societies at once during the course of this century could have a silver lining. The authors remember an old engineering proverb, "Better is the enemy of good enough." What can advanced industrial societies rapidly do that will be good enough to apply in the hard times ahead? Getting "good enough" off the dusty drawing boards of the Apollo Era is a first step. Here in the United States, an America, weary with wars and occupations, injured by storms along its Gulf Coast, chagrined by crumbling civil infrastructure, by returning to the Moon, accompanied by an Apollo Era-style upswing in knowledge and technology production, will let Americans see that the nation is being proactive and taking the lead concerning "big science" issues. Of course, these efforts must be tied in the political and public minds very early on to outer 
space production. Otherwise, doing "big science" to solve for those projects will be hampered by a lack of upgrade on the postsecondary education front and a loss of space infrastructure and systems. As the $21^{\text {st }}$ century plays out, the United States cannot afford a post-Orion Era.

As "planetary consciousness" increases owing to "big science" needs, an overlap between the environmental activist community and the space activist community will likely develop. That is because space is the "grand environment" in which the Earth is ensconced. And, though we scientists and engineers know that there is a natural "fit" between space products and concerns and environmental needs and concerns, a "public diplomacy" effort is needed to make an expedient connection in the eyes of the global public and politicians. Science, engineering, and scholarly societies, like the American Institute of Aeronautics and Astronautics can help facilitate this connective message.

\section{K. Solutions From Space}

Increased global warming effects, mega-sized disasters in heavily populated areas, and world energy needs will likely change the way the public and political leaders apprehend space. That is because spaceborne imaging systems envision the "big picture" for the average person that links it to the many human stories on the ground before, during, after events.

\section{Photos to right and below, courtesy:}

http://www.globalwarmingart.com/wiki/Glacier_Gallery (Antarctic Larsen B ice shelf break-up); www.abc.net.au/wa/stories/Hurricane_m1113173.jpg (Hurricane Katrina eye); outhouserag.typepad.com/.../pictures/index.html (man and dog on New Orleans Ninth Ward roof);

international.ucla.edu/asia/news/article.asp?... (Banda Aceh before and after images; Banda Aceh original satellite imagery, courtesy Digital Globe); www.abilityinfo.com/ticker/arch/archtsunami.html (homes and lives destroyed by the South Asian tsunami); http://news.nationalgeographic.com/news/2006/09/060914arcticice.html and rst.gsfc.nasa.gov/Sect16/Sect16_2.html (Shrinking north polar cap).
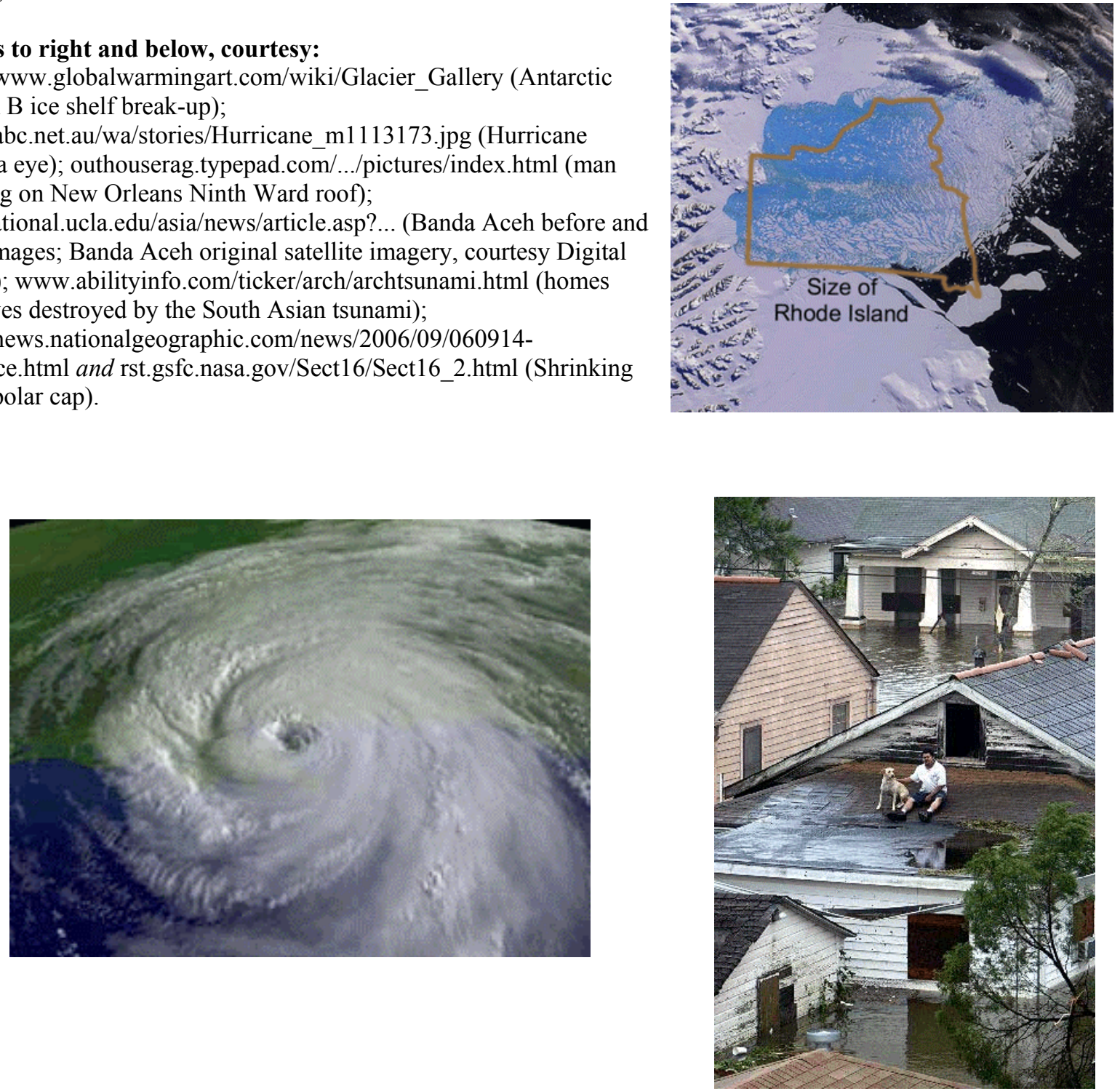

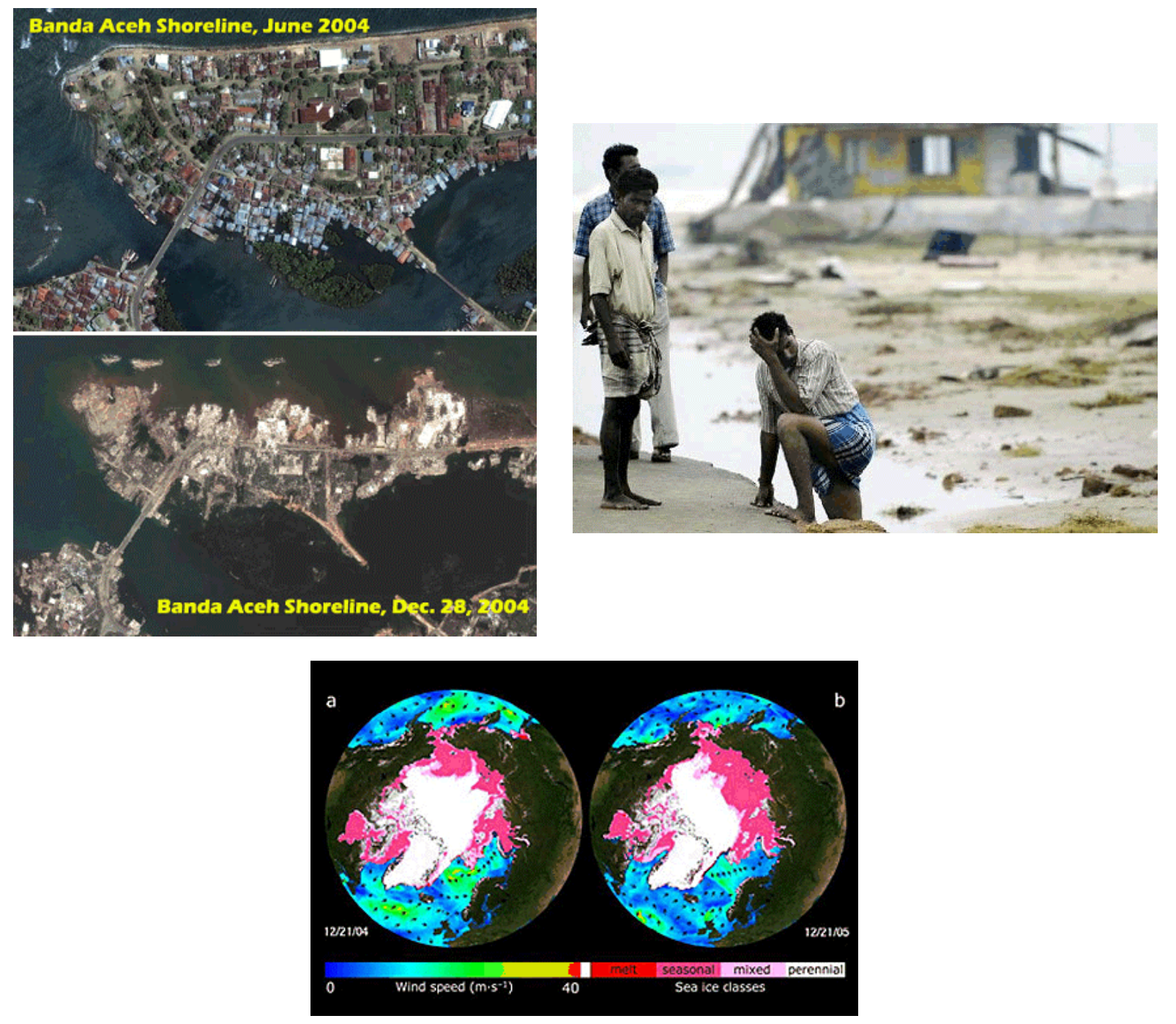

In the next few decades, we may expect tangible effects of global warming and of a world "running on empty" and a measure of spectacular disasters to come to the public eye via spaceborne imagery, television, and the Internet. In a world where a sense of powerlessness against the elements will come all too easy, energy will be a tangible symbol.

One energy source from space requires little research and development because, its proponents argue, that the space resources already exist (solar energy to microwaves). The other energy source from space (helium-3 fusion reactor fuel from the Moon) still require a good deal of research and development, if the helium-3 gas reserves can be found on the Moon and delivered to Earth.

Energy Sources From Space -- Solar Energy to Microwaves to Electricity. Petroleum is running out and there are efforts afoot to develop wide-scale usable alternatives. However, much of what passes as that effort among the traditional energy companies - the oil firms - is only so much "greenwash," fed by few resources. When the commodity that produces these energy companies' profits slows to a dribble, the inheritors of those companies can be expected to become more serious about refitting their energy companies to take advantage of other power sources. That constraint will open the door to opportunity. That is, if those companies are able to take action. The structures of oil companies have changed. According to Deffeyes (2005), "Within the oil industry, technological leadership has largely passed from the major oil companies to service companies like Schlumberger and Halliburton. The major oil companies are coming to resemble large service companies with attached merchant banks. Ownership of the oil production is a diminishing component of their income." 
In any event, as petroleum slows to a dribble, there is the potential for a transformation of capital, and of the ecology of capital, at this juncture. According to the entrepreneurial engineers of the Space Island Group, Low Earth Orbit (LEO) might be the new ecology of capital. ${ }^{\dagger+1+1+1+1+\dagger}$
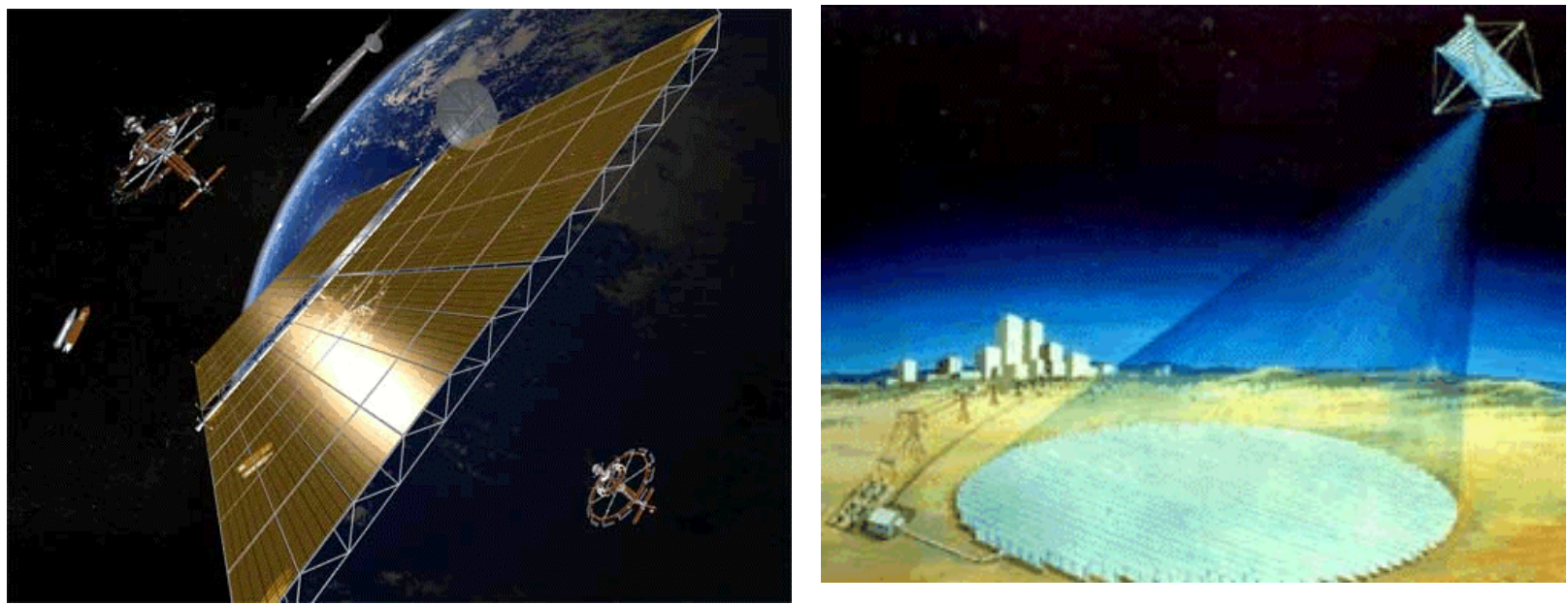

Left to right: Space Island Group's conceptualizations of space stations tending solar reflectors that then beam solar energy down in the form of microwaves for conversion to power to be sold at about ten cents per kilowatt hour.

In addition to Space Island Group's conceptualizations for a power system that originates in Low Earth Orbit, they think their spaceborne reflectors could provide continual sunlight to farms and commercial forestry operations and break up hurricanes, typhoons, and tornadoes by warming the air in their path to upset the heat balance upon which they survive.

Energy Sources From Space Helium-3 to Fusion Power to Electricity. Harrison Schmitt, who now pilots the research firm Interlune-Intermars Initiative, Inc., has said about helium-3, "There's enough in the Mare Tranquillitatis alone to last for several hundred years (Wakefield 2000)."

The isotope is rare on Earth, but has been deposited on the lunar surface in quantity over billions of years by the solar wind, the high-speed stream of charged particles flowing from the sun. Fusion research has been ongoing since the mid-20th century, first as a weapon of mass destruction, followed by interest in its possibilities as a means of power generation. The initial reaction of interest was hydrogen-2 (deuterium) and hydrogen-3 (tritium) fusing to form helium-4 and expelling a high-speed neutron:

$$
\mathrm{D}+\mathrm{T} \rightarrow{ }^{4} \mathrm{He}(3.5 \mathrm{MeV})+\mathrm{n}(14.1 \mathrm{MeV})
$$

The excess neutron constitutes a source of intense particle radiation. This is not particularly a concern in a thermonuclear weapon, where the intent is to inflict damage, and is even desirable in applications where the preferred kill mechanism is enhanced radiation versus heat and blast damage (the so-called neutron bomb). However, if the D-T reaction were to be sustained and controlled as a power source, it would necessitate heavy shielding; the excess neutron, having no electric charge, is not subject to being controlled by a magnetic field. Over time, as the shielding material absorbs neutrons, its non-radioactive nuclides are transmuted into radioactive ones, creating a waste problem. Some researchers have settled on helium-3 as a more practical fusion reaction for power generation:

$$
\mathrm{D}+{ }^{3} \mathrm{He} \rightarrow{ }^{4} \mathrm{He}(3.7 \mathrm{MeV})+\mathrm{p}(14.7 \mathrm{MeV})
$$

tht

1+t+1+t Wakefield, Julie. 2000. "Researchers and Space Enthusiasts See Helium-3 as the Perfect Fuel Source." Space.com, 30 June. Internet. Available from http://www.space.com/scienceastronomy/helium3_000630.html; accessed 30 January 2006. 
The reaction produces a helium- 4 nucleus, which is non-radioactive, and a proton, which is positively charged and

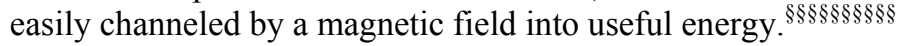

The problem is that only a few hundred kilograms of helium-3 are known to exist on Earth. Early indications are that the isotope is more plentiful on the lunar surface, although some skeptics question whether it exists in concentrations that would be commercially feasible to extract. It might be as ridiculously costly and technologically difficult to retrieve as the other half of the world's oil supply that stays in the ground in the form of droplets in reservoir rock (Deffeyes 2005, p. 27). ${ }^{25}$ Another barrier to commercial feasibility is getting more energy out of the reaction than is put into it to create the conditions for the reaction and to control it. Fusion only occurs at temperatures of several million degrees Celsius, an environment in which the electrostatic repulsion of nuclei is overcome and collisions can occur (claims for cold fusion reactions have not been reproduced). Thirty years ago, it was said that commercial fusion power generation was twenty to fifty years in the future; some say this is still a good estimate. Though, it would appear that development of fusion energy has been standing still. So, a new race for the Moon for alternative energy is being touted in the press, although it remains to be seen whether any vigorous Moon effort, either born of competition or of cooperation, is on the horizon.

Beyond the Moon and the occasional Near-Earth asteroid, the case for other solar system bodies being raw materials sources for Earth-based industry is weak due to the high cost of interplanetary transportation for the foreseeable future. It is a chicken-or-egg problem. Off-planet imports of raw materials to Earth will have to await a drastic reduction in transportation costs. It is a problem that a return exploration of the Moon can knock out of the chicken-or-egg cycle. That is because a relatively early prospect for overcoming the transportation barrier is helium3 on the Moon. Fusion-powered spaceships and off-world habitats would make solar system exploration a lot more doable. And, that would enable a quantum leap for humanity, as we will outline below. However, once again, the distribution, abundance, and availability of helium-3 is not well characterized, and the fusion power technology on which the commercial value of helium-3 is predicated may not be available for 20 to 50 years or more, if that. Another possibility is that a mature lunar industry might use lunar material for an economical source of materials for construction of solar power satellites that would transmit energy to Earth on a commercial basis - following up a technology that could have already been matured in Low Earth Orbit.

Of the two alternative energy resource plans from space, the solar power to microwaves to electricity scheme seems to be the more appealing held against the three downsides of the helium-3 plan:

- Fusion power generation appears to be stuck in a highly conceptual phase

- It is not known if helium-3 exists on the Moon in concentrations that can be easily and cost-effectively extracted

- The costs of transporting the fuel from the Moon and/or processing it there could be prohibitive

Yet, the Return-to-the-Moon to install some beachhead infrastructure might hold value for the United States just because other nation-states covet the Moon for an alternative energy source. Luan Enjie, vice-minister of China's Commission of Science, Technology and Industry for National Defense and director of the China National Aerospace Administration (CNAA), outlines China's lunar plans in an interview published by People's Daily. These plans include developing the Moon's supposed deposits of helium-3 as an energy resource (David 2003)

The Moon has become the focal point wherein future aerospace powers contend for strategic resources. The Moon contains various special resources for humanity to develop and use. [Helium-3] is a clean, efficient, safe and cheap new-type nuclear fusion fuel for mankind's future long-term use, and it will help change the energy structure of human society.

Nikolai Sevastyanov, former cosmonaut and current director of RKK Energiya, has stated that Russia is planning to mine helium-3 on the Moon by 2020 at a permanent base supported by a heavy-cargo transportation system: "We

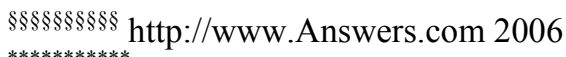

${ }^{* * * * * * * * * * *}$ David, Leonard. 2003. "China Outlines its Lunar Ambitions." Space.com, 4 March. Internet. Available from http://www.space.com/missionlaunches/china_moon_030304.html; accessed 30 January 2006. 
are planning to build a permanent base on the Moon by 2015 and by 2020 we can begin the industrial-scale delivery ... of the rare isotope helium-3 (Aljazeera 2006). ${ }^{\text {tit }}$

Petroleum supplanted whale oil for illumination and the lubrication of industrial machines. Nikola Tesla transformed capital further by taking us from DC to AC. If the effects from global warming and other challenges demonstrate a gradual progression of severity that is not overwhelming to the development of alternative resources and their infrastructures, then we may expect a transition from oil-based techno-economies to techno-economies originating from outer space production. Much hope is placed on new technological means of production like selfreplicating, self-repairing robots that extend even into the nanotechnological range (Dudley-Rowley and Colombano 2004). ${ }^{26}$ However, the broad landscape of nanotechnology is still virgin terrain, whose rather passive applications to date are found in suntan lotion, cosmetics, protective coatings, and stain resistant clothing. ${ }^{+1+1+1+1 !}$ Getting from those passive applications to utility in powering advanced industrial societies, adapting to epochal climate change and higher sea levels, and living off the planet is a great technological gulf yet to be bridged.

In the meantime, we have a good picture of how to mount energy infrastructure on orbit and connect to ground stations to power societies. We have a promising idea that helium-3 from the Moon can provide fusion power. Both near-term and longer-term solution to Earth's energy needs require the cost of pound-to-orbit to come down. If helium-3 is, indeed, a productive fuel, then a technology to get the contained gas off the lunar surface might be a mass driver. Sling the cargo off the Moon in a trajectory to be intercepted by a Moon-to-Earth orbit tug. However, building that infrastructure is part of the "poundage to orbit/space" problem and how it brews at the convergence of civil space, private enterprise, and oversight and cultivation of government.

Rising Sea Levels, Extreme Weather, and Disasters in Heavily Populated Areas. If sea levels rise slowly, there will be sufficient time to install berms, dikes, seawalls, levees, pumps, and technological solutions that make use of local and regional land features that will keep coastal lands usable for decades, and perhaps centuries. The sooner that construction is scoped out and begun, the better. A study in the April, 2007 issue of Environment and Urbanization reports that 634 million people live in coastal areas within 30 feet of sea level. The study also reported that about two-thirds of the world's cities of over five million people apiece are located in these low-lying coastal

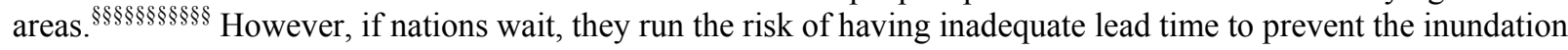
of cities and agricultural lands and the wholesale routs of millions of people who will become refugees in their own countries and in others. Monitoring planetary sea level rise through aerial and satellite imagery for the purposes of ameliorative construction is another manifest example of the globalization of space.

Those studying the 2004 South Asian tsunami from satellite data have conceived of innovations to make warning systems faster. The TOPEX/Poseidon and Jason- $1^{* * * * * * * * * * *}$ radar satellites passed over the Bay of Bengal soon after the Sumatran earthquake of 26 December 2004. That earthquake generated the South Asian tsunami. Examination of the imagery from those two satellites demonstrated the utility of combining real-time monitoring of radar satellite imagery with warning systems. The satellites captured measurements that allowed for the computation of the South Asian tsunami wave height in deep water, which indicated the energy punch it packed. Since the waves take time to

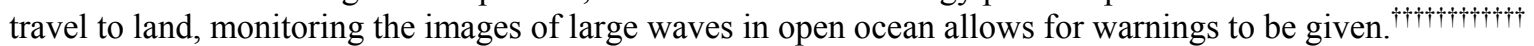

Satellite imagery of another kind is at the heart of space geodesist Geoffrey Blewitt's concept that could detect killer tsunamis in about 15 minutes' time. ${ }^{\text {totot+tott! }}$ Blewitt's concept works by measuring GPS satellite radio signals as they are broadcast during an undersea earthquake by GPS ground stations positioned around the globe. By accurately knowing the location of Global Positioning System satellites, how far GPS ground stations move during an earthquake, relative to the earthquake, can be measured. One can then calculate how big the earthquake is and how large a tsunami might be produced by it. Blewitt and collaborators at the Nevada Bureau of Mines and Geology and at the University of Nevada-Reno came up with the concept after analyzing GPS measurements from the South Asian tsunami. Blewitt and team's concept is an example of "good enough." A minimum of five GPS satellites are required to be in view of the ground station to accurately and swiftly predict the size of an earthquake. In practice, this condition is almost always satisfied. While new GPS ground stations cost about $\$ 10,000$ each, there are already stations in place that could contribute to the concept, if put into practice.

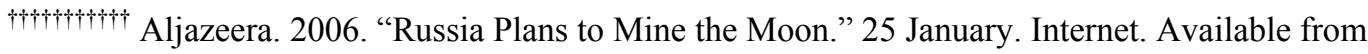
http://english.aljazeera.net/NR/exeres/65F240F9-CC80-4677-93D6-EBCACE8E7A45.htm; accessed 30 January 2006.

Wt+t+t $\mathrm{http}: / /$ en.wikipedia.org/wiki/Nanotechnology

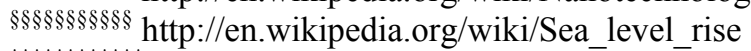

${ }^{* * * * * * * * * * * *}$ A collaboration between France and the United States.

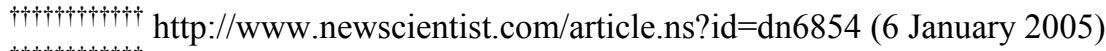

H+totto http://www.spectrum.ieee.org/oct06/4659 (Barry E. Gregorio) 
Downsides to satellite enhancement of tsunami warning systems are: 1) populated areas near the earthquake's epicenter would be struck within a few minutes, and 2) as the July 2006 Java tsunami taught, lack of local communications infrastructure prevented timely word getting out. ${ }^{\S \S \S \S \S \S \S \S \S \S \S}$ Five to six hundred people were killed during that event. The advantages, however, far outweigh the downsides. It took about three hours after the Sumatra earthquake for tsunami-height waves to begin hitting coastal areas in 2004. A lot fewer people would have been killed had satellite systems been brought to bear, than the nearly quarter million people who lost their lives in the South Asian event.

The best satellite imagery available, however, cannot beam people out of areas of impending natural disaster even when they get the word to evacuate in time. Bill Quigley, a civil and human rights lawyer and Professor of Law at Loyola University's New Orleans School of Law reported about his own five days trying to get out of New Orleans:

The Katrina evacuation was totally self-help. If you had the resources, a car, money and a place to go, you left. Over one million people evacuated - 80 to $90 \%$ of the population. No provisions were made for those who could not evacuate themselves. To this day no one has a reliable estimate of how many people were left behind in Katrina - that in itself says quite a bit about what happened.

Many tens of thousands of people were left behind in the New Orleans area to face Hurricane Katrina and, by best estimates, nearly half a million people have not returned. The moral of this and events like it, is that with "good enough" and "better" science and technology that will meet the challenges to our $21^{\text {st }}$ century world, "good enough" and "better" social investments in human beings must go hand-in-hand if people are to survive and become stakeholders in "big science" concerns. Detractors of space expenditures will argue: What is returning to the Moon and the other things, if, alongside those accomplishments, the poor, the elderly, the disabled, the sick, and the incarcerated are left in extreme circumstances, many to die as they did in New Orleans? In the United States, there are several things that could be done to ensure that social investments keep pace with the science and technology of expanding the human ecology. They are as follow:

- Easy accessibility to every level of education, K-12 through postdoctoral opportunities for people of all ages

- Funds and resources to and federal oversight over American postsecondary institutions to hire into secure teaching and /or research positions the $65 \%$ or more of the American professoriate who are not now in secure positions -- and the unknown percentage who are actually unemployed

- Reduction of unemployment over all sectors of the American work force that can address "big science" concerns

Something like the Emergency Conservation Work Act of 1933 that launched the Civilian Conservation Corps might have to be enacted to get America's large armies of unemployed and under-employed scholars, scientists, and engineers to work on the large-scale science projects necessary for the survival of advanced industrial civilization and humanity. Where the Civilian Conservation Corps focused on putting the armies of unemployed young American men to work on decimated American forests, a science, knowledge, and technology innovation corps would harness America's unemployed and under-employed mature brain trust to work on and teach about global warming, the decline side of oil, disaster mitigation, long-duration spaceflight, and all the other things we hold as necessary and desirable for civilization and humanity to endure.

The realities of new Earthly environments and the requirements of off-planet expansion of the human ecology can be met by some very basic social investments. If people are converted to the "knowledge troops" to battle extreme environments and secure jobs are made available so that they can continuously work the problems, then they will have health insurance, they can afford to relocate where and as needed, they will be able to purchase low gasoline consuming cars to evacuate from storm-surged cities, and all the rest. Rational social investment that meshes with "big science" concerns marches hand-in-hand with solutions and ameliorations all around.

$\S \S \S \S \S \S \S \S \S \S$ http://news.bbc.co.uk/2/hi/asia-pacific/5191190.stm (19 July 2006)

************* http://www.commondreams.org/views06/0221-36.htm (21 February 2006, "Six Months After Katrina: Who Was Left Behind - Then and Now" by Bill Quigley) 


\section{The Transnationalization of Space and the Technoeconomy-Technocracy Dichotomy}

The authors have argued in prior publications that innovation required for multi-year sustained long-duration space missions is along the lines of the same kind of innovation needed to respond to energy production and worsening environmental conditions and their unexpected consequences. We have previously pointed out that national and global efforts need to be made in earnest negotiation to form working day-to-day transnational funding, resources, and expertise relationships that make sustained long-duration space exploration actionable. NASA would be included as a partner agency in this transnational organization (Dudley-Rowley and Gangale 2006). ${ }^{27}$

Such an organization already exists to some degree and NASA already has a connection with it. And, this is the nuclear non-proliferation organization that was mentioned above. The authors have suggested that NASA explore and expand its link with the International Science and Technology Center (ISTC), an intergovernmental organization headquartered in Moscow, Russia, and whose governing board is chaired by Ronald Frank Lehman II, the Director of the Center for Global Security Research at the Department of Energy's Lawrence Livermore National Laboratory. ${ }^{1+\dagger+t+1 \dagger \dagger}$ And, it may be that something like this has begun to emerge stimulated by this prior link. In April 2006, NASA hosted an event to pull together the informal Global Explorations Strategy (GES) team, made up of 14 national space agencies. In March 2007, they met in Kyoto to draft a Framework for Collaboration. Besides the ESA and NASA, the other agencies involved were from Italy, Japan, China, Britain, France, India, Korea, Ukraine, Russia, Canada, Germany, and Australia.

Because human survival is at stake, the authors expect that most civil space and other "big science" projects will become cooperative ones involving all the countries named above and all others that can materially participate. We expect the management function among the cooperating national partners to fall to Europe through ESA channels for several reasons. That is because the ESA has a track record of cooperation among the world system of societies. Here in the United States, NASA has maintained a large administration and bureaucracy, an artifact of the Space Race years, which still burdens its budgets and slows its activities. ESA was never involved in large-scale political activity such as the Space Race, so it has always had a small and efficient decentralized structure. Its size is comparable to a private company and many of its projects are allocated over different organizations in several European countries. The ESA coordinates these projects while not directly employing the people involved in them. Because it has management expertise over different European space agencies in the day-to-day, on top of its nonEuropean partnerships, we expect it to become the manager of transnational "big science" projects.

The technoeconomy-technocracy dichotomy described earlier is not absolute; there is a push-pull relationship. Our walkabout the cosmos may be a series of complimentary steps, the left foot of technocracy followed by the right foot of technoeconomy. Furthermore, it is possible that a transnational project for the human exploration of the Moon and Mars might include not only nation-state partners, but corporate partners. Socializing some portion of the investment may incentivize private interests to put some of their own skin in the game. Non-governmental organizations (NGOs), while commanding far smaller resources, might nevertheless find useful roles. As human space projects become larger, more complex, and more expensive, programmatically spanning several decades, the political-economic issues of funding continuity, and the organizational challenges of strategic partnerships between government agencies, private enterprises, and NGOs, all of different nationalities, become more challenging as well. There will be trade-offs.

For instance, in return for the multiplicity of funding sources and the stability this provides, there will be a loss of programmatic flexibility. This is not necessarily all bad. The US Congress funds projects from year to year, and it can be feast or famine, depending on the political deals that are made in the corridors and the anterooms of the Capitol. Programs can be slowed down or knocked off track, then in the next fiscal year receive full funding. This is no way to run a development program. Every such program has an optimum funding curve that optimizes cost, schedule, and technical risk. Any deviation from that curve results in an increase of one, and usually more, of these three factors. If you speed up the project, it costs money. If you slow down the project, it costs money. Such deviations are the norm, not the exception, in federally-funded projects.

At the "New Trends in Astrodynamics II" Symposium held at Princeton University in June 2005, Hayden Planetarium director Neil deGrasse Tyson, who served on the President's Commission on Implementation of United States Space Exploration Policy (Aldridge Commission), which issued its report in 2004, gave a presentation on George W. Bush's "New Vision for the Space Exploration Program" (not published in the symposium's proceedings). As I recall, he discussed how the administration's goals regarding the human exploration of the Moon and Mars would be accomplished with modest, sustainable funding. That sounds fine as far as it goes, but if funding

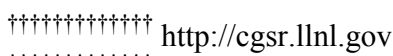

W+1+t+t+ http://www.theregister.co.uk/2007/03/15/space_collaboration/ 
should become an issue, i.e., when the program hits some technical snag that is more difficult than anticipated and therefore more expensive to solve, Tyson responded, "We'll just stretch it out."

This is great grist for the space libertarian mill, for it calls into question the credibility of the government's commitment to human space exploration. Any technical manager understands that one budgets a certain percentage of a project's schedule and money as "management reserve." This is the insurance policy to handle the "unknown unknowns," the unanticipated technical challenges. In the long run, management reserve saves money, because when it has to be spent, it keeps the project on its optimum curve.

"Stretching it out" costs money. The International Space Station (ISS) is a splendid example of this. The project began in 1984, and was targeted to be completed in 1994 at a cost of $\$ 14.5$ billion. It is not yet completed, is considerably down-scoped from its original design (which includes modules originally designed for the Soviet Mir 2 ), and it is now expected to cost over $\$ 30$ billion (Young et al. 2001). ${ }^{\$ \$ \$ \$ \$ \$ \$ \$ \$ \$ \$ \$ \S ~ T h i s ~ i s ~ j u s t ~ t h e ~ c o s t ~ o v e r r u n ~ t o ~ t h e ~}$ American taxpayer. Our partners in space projects have suffered. The schedule slips on the American side have caused cost overruns in the Russian, European, Japanese, and Canadian components of the ISS. The European Space Agency's (ESA) history of cooperation with NASA has been particularly disappointing. ESA developed the Spacelab for the Space Shuttle as a modular, versatile, multi-mission series of payloads capable of many re-flights. Because the Space Shuttle proved incapable of operating the high number of missions per year that was envisioned in the original traffic models, and Spacelab missions were a low priority for the US government compared to the Shuttle-specific designs of certain national security spacecraft, NASA flew only a handful of Spacelab missions. As a result, ESA invested a lot of money and received very little return. If they know what is good for them, national governmental and transnational corporate partners will hold the US government's feet to the fire on any future space projects by insisting on serious and enforceable contractual consequences to material breaches. In a multiple funding source project, all parties should commit to full funding of their assigned portions from one major programmatic milestone to the next, as defined in a commonly-used project management document such as MILSTD-1521B: system design reviews, preliminary design reviews, critical design reviews, et cetera (USAF 1985). ${ }^{* * * * * * * * * * * * *}$ At each of these decision points, the parties should reach a consensus as to whether the project should continue to the next major milestone with full funding.

"Stretching it out" and inadequate cost and schedule flexibility can even end up costing lives:

The Lady Franklin Bay Expedition in the Eastern [Canadian] Arctic [1881-1884] was organized in response to an international polar science project. Officially mandated, it was shabbily put in motion because of Congressional and military mis-coordination. When the expedition got in trouble owing to the bumbling of the pick-up ships under the command of the U.S. Navy, the government simply abandoned 25 healthy expeditioners. As a result, only seven men survived, and Commander Adolphus Greeley has gone down in popular history with the "bum rap" of being an incompetent leader. Digging into the facts of the expedition, however, one finds that it was the efforts of Greeley's wife, who through much networking and private means, got a bounty imposed among international naval, whaling, and trading vessels for the rescue of the party. Without her effort, there would have been no survivors (Dudley-Rowley 1999). ${ }^{28}$

It may be that the next great decision regarding outer space is also not so much about the man, but about the moment and the machine. The technologies are in hand to accomplish extraordinary things in outer space. All we have to do is integrate those technologies, build the infrastructure and the vehicles, train the ground and flight crews, and go. Oh, and one more thing... add money. And this is where we come down to the hardest questions. Who pays? Who benefits? What are the socioeconomic forces that will bring about the next surge into space?

Now, it is a sociological fact that just because societies have on-the-shelf technologies to deploy, it does not follow that they will deploy them. Political, economic, and other forces, perceived and actual, have always delayed or denied entrée to some technologies in many societies throughout

$\S \S \S \S \S \S \S \S \S \S \S \S$ Young, A. Thomas et al. 2001. Report by the International Space Station (ISS) Management and Cost Evaluation (IMCE) Task Force.” Internet. Available from http:/history.nasa.gov/youngrep.pdf; accessed 20 March 2006.

${ }^{* * * * * * * * * * * * * *}$ United States Air Force. 1985. MIL-STD-1521B (USAF), "Military Standard: Technical Reviews and Audits for Systems, Equipments, and Computer Software." 4 June. Internet. Available from http://sparc.airtime.co.uk/users/wysywig/1521b.htm; accessed 21 March 2006. 
history. On the other hand, political, economic, and other forces are shaped by technology and technological feasibility (Dudley-Rowley 2001). ${ }^{\text {tोitititititi }}$

The authors estimate that the moment is now and the decades of this century to follow. Socioeconomic forces can be expected to marshal as coastal towns and cities are inundated, as thousands and millions are refugee'd, as infrastructure in mature advanced industrial societies decline and crumble from the paucity of the things that make them run, and as infrastructure in new advanced industrial societies awe a world undergoing epochal climate change. Necessity will demand a focused response from those who can produce knowledge and pass it on. And, what will happen next will not only see a human presence elsewhere off the planet, but also will usher in a new economic modality, therefore transforming capital, and which will change the world system of societies.

\section{The Rise of a Multi-Planet Economy}

When pockets of people begin living sustainably off the Earth, an extraglobalization process begins to occur. If globalization is the increasing interconnectedness of Earthly societies and the globalization of space is how globalization has altered the space endeavor, then extraglobalization is the extension of these intertwined phenomena to those sustaining themselves indefinitely off the Earth and the dialectic - the multilectic, if you will -set up among them and the Earth.

Let us look forward to a distant time when low transportation costs make the extraction of primary resources from celestial bodies economically feasible. In the past, colonization led to exploitative relationships, in which colonial powers took advantage of cheap, unskilled labor in the colonies to extract raw materials. These residual trade relationships have persisted into the 21st century. Immanuel Wallerstein (1999) refers to the industrial core of the capitalist world-system, the semi-periphery of lesser industrialized states, and the underdeveloped periphery. However, space settlements will be high-tech by their very nature, and will be populated by highly-educated, highlyskilled workforces. Thus, once settlements are able to provide for their own subsistence, they will be able to turn to high value-added productive activities, many of which will be competitive with terrestrial products elsewhere in the solar system due to gravitational advantage.

Should settlements develop on the Moon and Mars and even elsewhere, the most credible use of celestial resources is for either local use or use elsewhere in space. In the absence of commercial revenue from direct trade with Earth, interplanetary trade not involving Earth directly would necessarily involve government contracts to private companies to provide goods and services to government-owned operations. Earth is the source of investment capital for outer space, and the accumulation of hard currency in outer space will require the creation and exchange of something that is of value to Earth. It is such productive activities that must form the basis of a largely commercial, non-governmental, solar system economy.

As commercial interplanetary trade develops, interesting avenues of speculation arise. Adam Smith (1776) explained how two countries could profit in trading with each other by using their absolute advantages over each other in producing different commodities. For instance, consider two planets, A and B, each capable of producing commodities 1 and 2 (see Table 3 below). With production time held constant and neglecting transportation costs, on Planet A, the average worker is capable of producing 250 units of Commodity 1, whereas on Planet B, the average worker is capable of producing 150 units of Commodity 1. Planet A enjoys an absolute advantage over Planet B in Commodity 1, since its workers are more efficient in producing that commodity. On the other hand, on Planet A, the average worker is capable of producing 100 units of Commodity 2, whereas on Planet B, the average worker is capable of producing 200 units of Commodity 2. Planet B enjoys an absolute advantage over Planet A in Commodity 2. If Planet A and Planet B do not trade, and each divides its workforce of 200,000 people in half to produce each commodity, they will produce 40 million units of Commodity 1 and 30 million units of Commodity 2 . However, if Planet A and Planet B do trade, they can specialize in producing the commodity in which they enjoy absolute advantage, thereby producing 50 million units of Commodity 1 and 40 million units of Commodity 2 . Both planets profit from trade. Each is buying a cheaper commodity from the other than it could produce. Productivity increases on both planets.

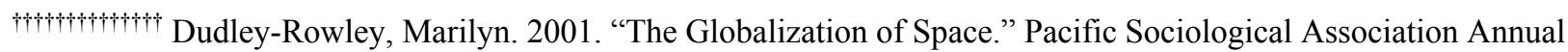
Conference, San Francisco, California, 30 March. Internet. Available from http://www.opsalaska.com/GlobalizationOfSpace/PacSoc.htm; accessed 3 July 2005. 


\begin{tabular}{|c|c|c|c|}
\hline \multicolumn{4}{|c|}{ Production Rates } \\
\hline & $\begin{array}{l}\text { Planet A } \\
\text { (units/worker) }\end{array}$ & $\begin{array}{l}\text { Planet B } \\
\text { (units/worker) }\end{array}$ & \\
\hline Commodity 1 & 250 & 150 & \\
\hline Commodity 2 & 100 & 200 & \\
\hline \multicolumn{4}{|c|}{ Production Without Trade } \\
\hline & Planet A (units) & Planet B (units) & Total (units) \\
\hline Commodity 1 & $25,000,000$ & $15,000,000$ & $40,000,000$ \\
\hline Commodity 2 & $10,000,000$ & $20,000,000$ & $30,000,000$ \\
\hline \multicolumn{4}{|c|}{ Production With Trade } \\
\hline & Planet A (units) & Planet B (units) & Total (units) \\
\hline Commodity 1 & $50,000,000$ & 0 & $50,000,000$ \\
\hline Commodity 2 & 0 & $40,000,000$ & $40,000,000$ \\
\hline
\end{tabular}

\section{Table 3. Absolute Advantage}

Now suppose that on Planet A, the average worker is capable of producing 1200 units of Commodity 3 , whereas on Planet B, the average worker is capable of producing 200 units of Commodity 3 (see Table 4 below). Planet A enjoys an absolute advantage over Planet B in Commodity 3. Also, on Planet A, the average worker is capable of producing 300 units of Commodity 4, whereas on Planet B, the average worker is capable of producing 100 units of Commodity 4. Planet A enjoys an absolute advantage over Planet B in Commodity 4.

\begin{tabular}{|l|l|l|}
\hline & Planet A (units) & Planet B (units) \\
\hline Commodity 3 & $1,200,000$ & 200,000 \\
\hline Commodity 4 & 300,000 & 100,000 \\
\hline
\end{tabular}

\section{Table 4. Comparative Advantage}

Planet A is more efficient at producing both commodities. Why should it trade with Planet B? Planet A would lose the opportunity to produce four units of Commodity 3 to produce one unit of Commodity 4, but Planet B would lose the opportunity to produce only two units of Commodity 3 to produce one unit of Commodity 4 . It is relatively cheaper for Planet A to import Planet B's Commodity 4, because it minimizes the lost opportunity to produce Commodity 3. It is the production ratios within the two economies that make comparative advantage work. Planet B also profits from trading with Planet A, since Planet A's Commodity 3 is cheaper than Planet B's Commodity 3.

David Ricardo's (1817) ${ }^{\$+1+1+1+1+1 !}$ model of comparative advantage was valid on Earth in the days when capital was for the most part restricted to the borders of one country. It does not work the same way when capital is mobile as it is today. Capital moves to where labor is cheapest, thus jobs are lost, and the displaced workers may not find work in other industries. In any case, absolute and comparative advantages can fluctuate with the cost of materials, cost of capital, cost of labor, skill level, and other factors.

Meanwhile, there is an additional complexity when it comes to interplanetary trade. Extremely problematic environmental factors such as high atmospheric pressure (Venus, Jupiter, Saturn, Uranus, and Neptune) or extremely long travel times (Pluto and 2003 UB313) will probably delay the establishment of settlement on these planets indefinitely. Even promising terrestrial-like moons of Jupiter might be off-limits owing to the magnetosphere of this gas giant that offers a deadly radiation environment for human explorers. The remaining list of celestial bodies on which settlements might be established are Mercury, the Moon, Mars and its satellites, and various

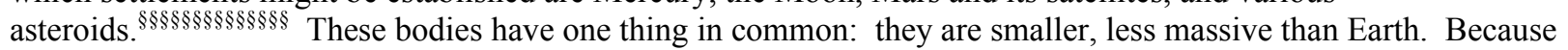
of this, they have less powerful gravitational fields, thus it takes less fuel to land on and launch from them, which makes them less expensive ports for moving goods. This translates as a permanent, gravitational advantage. Nature imposes a permanent, nonreciprocal tariff on terrestrial goods shipped to these bodies. As a result, it will be less

+m+tont+t Ricardo, David. 1817. On the Principles of Political Economy and Taxation. Internet. Available from http://internationalecon.com/v1.0/ch40/40c000.html; accessed 16 March 2006.

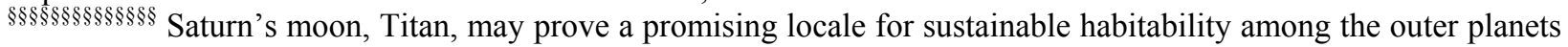
since Saturn's magnetosphere is different than Jupiter's ("Saturn: Magnetic Field and Magnetosphere," by C.T. Russell and J.G. Luhmann, http://www-ssc.igpp.ucla.edu/personnel/russell/papers/sat_mag.html). 
expensive for extraterrestrial settlements to ship goods to each other and to Earth than it will be for Earth to ship goods to them. There may be persistent trade deficits/surpluses between planets. This situation has no analogue on Earth. Transoceanic cargo ships do not have to steam uphill on one leg of a voyage, nor do they have the advantage of gliding downhill on another. Of course there are ocean currents and prevailing winds, but these are negligible in comparison with the differences between the planets in their gravity wells.

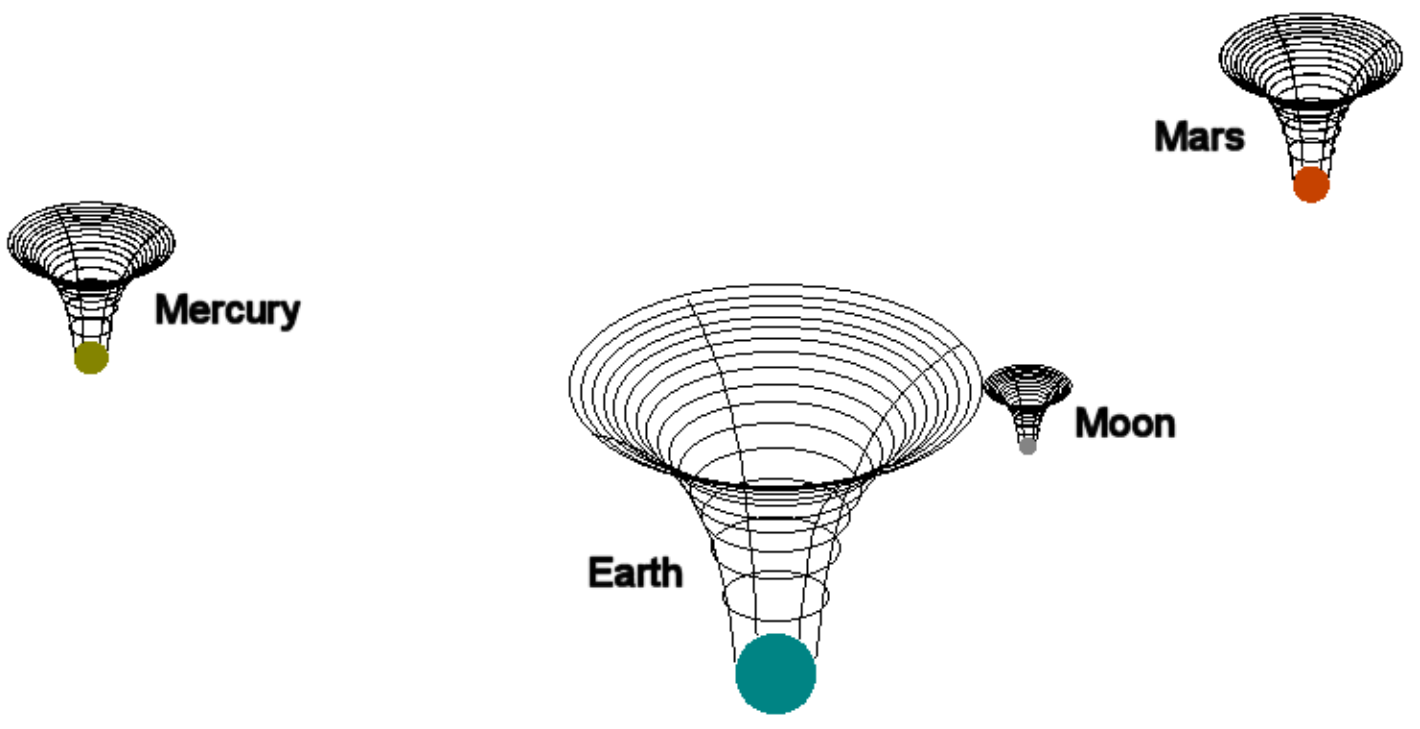

\section{Figure 7: Gravity Wells}

To begin the analysis, we use Konstantin E. Tsiolkovskij's rocket equation:

$$
\Delta v=v_{e} \ln \quad \frac{m_{0}}{m_{1}}
$$

where:

$m_{0}=$ initial total mass

$m_{1}=$ final total mass

$\Delta v=$ integration over time of the magnitude of the acceleration produced by using the rocket engine

$v_{\mathrm{e}}=$ velocity of the rocket exhaust with respect to the rocket (the specific impulse, or, if measured in time, that multiplied by gravity-on-Earth acceleration)

Solving for $m_{1}$, the final total mass:

$$
m_{1=} m_{0} \quad e^{-\Delta v / \Delta v_{\mathrm{e}}}
$$

Let us assume that the same rocket propellants are used everywhere, thus $v_{\mathrm{e}}$ can be held constant. The ratio of the masses that can propelled from one planet to another with the same amount of propellant is thus dependent on the difference in their escape velocities (see Table 5 below) is given by:

$$
\overline{m_{\mathrm{p} 1}}=e\left(\Delta v_{\mathrm{p} 2}-\Delta v_{\mathrm{p} 1}\right)
$$


This equation gives a first approximation of the gravitational advantage of one planet over another. Planet-to-planet values are given in Table 6 . Second order terms would include taking into consideration such things as the relative expense of descent modes (aerobraking, parachute, and braking propulsion for Earth and Mars, braking propulsion only for the Moon and Mercury). Another consideration to bear in mind is that the ratios in Table 5 assume the same propulsion systems throughout the system.

\begin{tabular}{|l|l|l|}
\hline & $\begin{array}{l}\text { Surface } \\
\text { Gravity } \\
\left(\mathbf{m} / \mathbf{s}^{\mathbf{2}}\right)\end{array}$ & $\begin{array}{l}\text { Escape } \\
\text { Velocity } \\
(\mathbf{k m} / \mathbf{s})\end{array}$ \\
\hline Mercury & 3.701 & 4.435 \\
\hline Earth & 9.7801 & 11.186 \\
\hline Moon & 1.622 & 2.38 \\
\hline Mars & 3.69 & 5.027 \\
\hline
\end{tabular}

Table 5. Surface Gravity and Escape Velocity

\begin{tabular}{|l|l|l|l|l|}
\hline $\begin{array}{c}\text { To } \rightarrow \\
\text { From } \\
\downarrow\end{array}$ & Mercury & Earth & Moon & Mars \\
\hline Mercury & & 854.91 & 0.12809 & 1.8076 \\
\hline Earth & 0.00117 & & 0.00015 & 0.0021 \\
\hline Moon & 7.80684 & 6674.17 & & 14.1116 \\
\hline Mars & 0.55322 & 472.96 & 0.07086 & \\
\hline
\end{tabular}

Table 6. Gravitational Advantage

The Moon's gravitational advantage might be enhanced by the use of mass drivers, a form of electromagnetic propulsion rather than chemical propulsion. Also, the development of scramjet technology could mitigate Earth's gravitational disadvantage.

The most immediate effects to Earth of a mature human presence on other celestial bodies in the solar system will be governmental and economical, impacting the nation-state system.

Medieval Europe was characterized by the feudal mode of production. Sovereignty was dynastic, property belonged to hereditary nobilities, and productive labor was performed by serfs who were bound to the land. The overarching power was the Catholic Church, including its secular subsidiary, the Holy Roman Empire. The rise of the capitalist mode of production in towns and the interstate trade between them created new sources and stores of wealth rivaling those of the landed nobility. The rise of city-states and city-leagues challenged the power of the dynastic states and the Empire. The rise of literacy in the growing cities challenged the religious authority of the Church. An important result of the 1648 Peace of Westphalia that ended the Thirty Years' War was that it laid to rest the idea of the Holy Roman Empire having secular dominion over all of Western Christendom. The loss of this overarching structure created the necessity for feudal entities to coalesce into larger, more centralized states to defend against each other. Imperial free cities were no longer adequately protected by the Empire, and joined the larger states that were forming. Spruyt (1994) ${ }^{29}$ writes as follows:

At the end of the feudal era, a dramatic economic change occurred. Localized barter exchange started to give way to monetary exchange and translocal trade. By the beginning of the fourteenth century, a variety of new institutional forms had emerged for organizing political and economic life. Sovereign territorial states, city-leagues, and city-states all tried to tap into the new sources of economic wealth, particularly long-distance trade. Indeed, the city-based political organizations initially did very well. In the long run, however, roughly by the middle of the seventeenth century, city-states and city-leagues had fallen by the wayside.... 
I argue that the sovereign territorial state prevailed because it proved more effective at preventing defection by its members, reducing internal transaction costs, and making credible commitments to other units.... [S]overeign rulers were better at centralizing jurisdiction and authority.

Consequently, they were in a better position to prevent free riding and to gradually rationalize their economies and standardize coinage and weights and measures. This economic rationalization corresponded with a greater capacity to wage war. The institutional makeup of sovereign territorial states thus gave them competitive advantages over other organizational possibilities.

The so-called nation-state system was born. However, Spruyt's use of the more general term "sovereign territorial state" is more appropriate.

A nation-state is a specific form of state (a political entity), which exists to provide a sovereign territory for a particular nation (a cultural entity), and which derives its legitimacy from that function.... Typically it is a unitary state with a single system of law and government. It is almost by definition a sovereign state, meaning that there is no external authority above the state itself.

...The nation-state implies the parallel occurrence of a state and a nation. In the ideal nation-state, the population consists of the nation and only of the nation: the state not only houses it, but protects it and its national identity (i.e., they coincide exactly): every member of the nation is a permanent resident of the nation-state, and no member of the nation permanently resides outside it. There are no ideal nation-states, but examples of near ideal nation-states might include Japan and Iceland. This ideal has influenced almost all existing sovereign states, and they cannot be understood without reference to that model.... Thus, the term nation-state is also used, imprecisely, for a state that attempts to promote a single national identity, often beginning with a single national language.

There are many states in today's international system that are not nation-states in the strict sense. At one end of the spectrum are the principalities of Liechtenstein, Andorra, and Monaco, and the republics of San Marino and Singapore. Numerous territorial states contain many national groups, the United Kingdom and the Russian Federation being two examples. Switzerland, whose independence was recognized in the Peace of Westphalia, has no common language. The United States has historically boasted of being the "melting pot" of cultures. However, in keeping with general usage, sovereign states will continue to be referred to as "nation-states," and the system of relations between them as the "international system" or the "nation-state system."

Marxist ideology predicted the ultimate demise of the Westphalian system, to be replaced by an international workers' union; however, the capitalist world-system has outlived the centrally-planned economic system. Ironically, capitalist globalization has often been cited as a process that threatens the sovereignty of the state, and therefore has great implications for the future character of the nation-state system. By the late 20th century, transnational production systems had enhanced the ability of corporations to bypass the nationally-based political influence of trade unions and environmental movements. In the view of many scholars, the various interrelated processes of globalization, which are making national borders more porous to trade in goods and services, to capital, and to information, including sociopolitical ideas and norms, are rendering the nation-state increasingly less relevant. Gilpin $(2000, \text { p. } 22)^{30}$ writes:

As a consequence, multinational firms have become extremely important in determining the economic, political, and social welfare of many nations. Controlling much of the world's investment capital, technology, and access to global markets, such firms have become major players not only in international economic, but political affairs as well.

Steger (2000, pp. 28-29) ${ }^{31}$ writes:

Most of the debate on political globalization involves the weighing of conflicting evidence with regard to the fate of the modern nation-state. In particular, two questions have moved to the top of the research agenda. First, what are the political causes for the massive flows of capital, money,

\footnotetext{
Wikipedia. 2006a. "Nation-State." Internet. Available from http://en.wikipedia.org/wiki/Nation-state;
} accessed 18 March 2006. 
and technology across territorial boundaries? Second, do these flows constitute a serious challenge to the power of the nation-state? These questions imply that economic globalization might be leading to the reduced control of national governments over economic policy. The latter question, in particular, involves an important subset of issues pertaining to the principle of state sovereignty, the growing impact of intergovernmental organizations, and the prospects for global governance.

One influential group of scholars sees politics as being "rendered almost powerless in the face of an unstoppable and irreversible technoeconomic juggernaut that will crush all governmental attempts to reintroduce restrictive policies and regulations." And, not only are political institutions no longer in control of national economies, but now economic interests are in control of national policies. According to this view, we are now "in a new phase in world history in which the role of government will be reduced to that of a handmaiden to free-market forces (Steger 2000, p. 29)." Not that this is a particularly novel insight, for Karl Marx characterized government as the handmaiden of the bourgeoisie a century and a half ago, as the 19th century era of globalization was in full swing. In any case, in the most extreme expression of this view, national borders will ultimately cease to be meaningful concepts, and the fate of the planet will be entirely in the hands of global capitalist forces.

Meanwhile, the propensity of the nation-state system to fence off peoples from each other and to organize them for aggressive purposes has been remarked upon by many. The unparalleled destructiveness of the 20th century wars led some to question the nation-state's ability to deliver on a state's most basic raison d'être: security. European leaders in particular have been crafting a system of political integration that is transcending the nation-

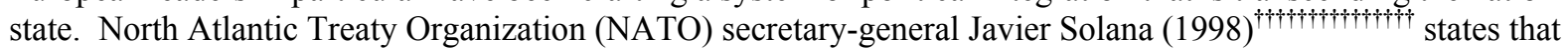
"humanity and democracy [were] two principles essentially irrelevant to the original Westphalian order.... [T] he principle of sovereignty it relied on... produced the basis for rivalry, not community of states; exclusion, not integration." German Foreign Minister Joschka Fischer (2000) be obsolete:

The core of the concept of Europe after 1945 was and still is a rejection of the European balanceof-power principle and the hegemonic ambitions of individual states that had emerged following the Peace of Westphalia in 1648, a rejection which took the form of closer meshing of vital interests and the transfer of nation-state sovereign rights to supranational European institutions.

The "Clash of Civilizations" envisioned by Samuel P. Huntington (1993) 32 as manifested in the War on Terrorism has given rise to a new threat to the international system. Following the 11 March 2004 terror bombings in Madrid, a self-proclaimed al-Qaeda spokesperson has declared that "the international system built-up by the West since the Treaty of Westphalia will collapse; and a new international system will rise under the leadership of a

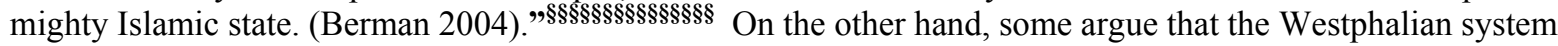
collapsed with the disintegration of the Soviet Union, which left the United States as the global hegemon. Certainly Yugoslavia in the late 1990s had, and Afghanistan and Iraq in the first years of the 21st century have, whatever sovereignty the sole superpower has suffered them to exercise.

Jorg Friedrichs $(2001)^{33}$ offers a novel perspective on the complex and fluid state of affairs. He notes that neither conventional international relations theory nor the discourse about globalization seem able to account for the apparent contradictions between globalization, fragmentation, and sovereign statehood. As a conceptual alternative,

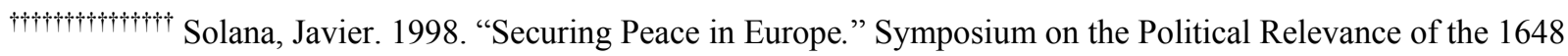
Peace of Westphalia, Münster, 12 November. Internet. Available from http://www.nato.int/docu/speech/1998/s981112a.htm; accessed 18 March 2006.

tmotomotot Fischer, Joschka. 2000. "From Confederacy to Federation - Thoughts on the Finality of European Integration." Speech Humboldt University, Berlin, 12 May. Internet. Available from http://www.auswaertigesamt.de/www/en/eu_politik/ausgabe_archiv?suche=1\&archiv_id=1027\&bereich_id=4\&type_id=3; accessed 19 March 2006.

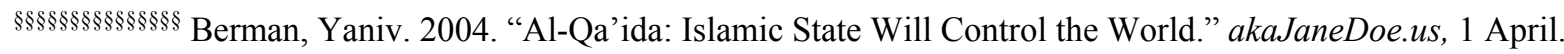
Internet. Available from http://akajanedoe.us/islamicjihad12.html; accessed 19 March 2006. 
he introduces the idea of 'new medievalism,' in the sense that today's system is characterized by overlapping authority and multiple loyalty, held together by a duality of competing universalistic claims, much as:

...the Middle Ages were characterized by a highly fragmented and decentralized network of sociopolitical relationships, held together by the competing universalistic claims of the Empire and the Church. In an analogous way, the post-international world is characterized by a complicated web of societal identities, held together by the antagonistic organizational claims of the nationstate system and the transnational market economy. New medievalism provides a conceptual synthesis which hopefully transcends some of the current deadlocks of IR theory and, at the same time, goes beyond the fundamental limitations of the globalization discourse.

Lifting our gaze skyward, the question arises, what forms of governance shall we take with us, and what shall we leave behind? We have an opportunity for a revolution in human thought regarding human nature and human rights, the relationship of individual, society, and state, and to question the factors of production, the means of production, and modes of production. In short, as one writer on outer space law has remarked to the authors, we get to do the Enlightenment over again. Stewart B. Whitney (1984, pp. 11-12) ${ }^{34}$ wrote:

We can challenge sociology to provide the conceptual basis of the social design for space settlement, to construct social models required for the successful adaptation of Humankind to space. Planning the social design of space settlements is necessary for the success of space industrialization; without appropriate social organization, accomplishment of industrialization tasks will fail.

Rational planning for the social design of space settlements must rest on the knowledge of social scientists and scholars. This requirement presents a particularly difficult problem for those who plan the social aspects of space settlements. This does not constitute an insurmountable difficulty, however, because knowledge of human social responses to various types of problems and difficulties is available; this knowledge can be applied to analysis of the unique problems that are likely to require societal resolution in space settlements from which logical models of social design can be developed. These logical models can serve as a starting point for social planning and can be modified as additional knowledge and insight are developed.

What were the forces and conditions present in the 17th and 18th centuries that set the Enlightenment in motion? Are there analogous forces and conditions present in the 21 st century that might set in motion a new Enlightenment?

From the early 16th to the mid-17th centuries, Europe was ravaged by religious wars and civil wars as the Protestant Reformation broke the temporal power of the Catholic Church, as well as its hold over knowledge and learning. Stepping into the voids left by the fading of the feudal order and the Holy Roman Empire were the nationstate political system, the capitalist production system, and the scientific knowledge system. The new order solved old problems and created new ones. There were still wars, persecutions, and injustices, and if anything, the problem of war was exacerbated. Whereas feudal lords were rarely able to raise armies of more than a few tens of thousands, a particular advantage of the nation-state was its ability to mobilize millions in the machinery of death, and its principal evil was its propensity to set that machine in motion again and again.

The Enlightenment occurred just as a new ecological opportunity was opening for the Westphalian system. European colonies in the New World were reaching a level of development at which they could challenge their mother countries and gain independence. These new American nation-states were distinctly different in character from their European antecedents; whereas most of Europe was ruled by hereditary monarchs, the American states were theoretically republics. ${ }^{* * * * * * * * * * * * * * *}$ With varying degrees of success, the ideals of the Enlightenment were expressed in the political entities that sprouted from the new soil of the Americas. A century and half after its birth, the strongest of these American republics was able to intervene decisively in a war that was devastating Europe, to do so again a generation later to defeat one form of totalitarianism, and to protect half of the continent for two more generations from another form of totalitarianism. Today, in its continuing lead role in NATO, the United States acts as the guarantor of European stability as the continent's institutions expand their membership and deepen their level of integration. Europe is a union of peaceful, liberal, democratic states.

\footnotetext{
**************** The Empire of Brazil, 1822-1889, proclaimed by Pedro I and later ruled by his son Pedro II, was a
} notable exception. 
Here on Earth, we face in the 21 st century a possible receding of the nation-state system as international borders become more porous to trade, travel, and information. On top of this, humankind stands on the threshold of expanding into the new ecologies of the solar system. The nation-state does not exist out there, and the current body of international law makes it doubtful that it ever will. Since Article II of the Outer Space Treaty Outer prohibits "national appropriation by claim of sovereignty," it seems that there can be no national sovereignty. As strange as it may sound, it appears that the nation-state has chosen not to extend itself into the cosmos, but to restrict itself to Earth. Seara Vázquez ${ }^{35}$ wrote $(1965,232)$ :

What is the reason for [the] renunciation of the right to the occupation of a res nullius for the particular benefit of one state? It might be judicial — a more lofty concept of justice and of international solidarity. It might be economic - the enormous cost of astronautic enterprises, which would make it difficult for a single nation to sustain the expenses involved.

It is almost certain that the reason is political; the two principal protagonists in international politics today, the United States and Russia, do not yet know with certainty who will be the first to arrive and, mutually fearing the result of a triumph by the adversary, are trying to bring all the nations into the game, thus making a common cause with the winner and reducing the risks.

It is vital, however, not to discard the possibility that this is due to an awakening of the universal legal conscience to the possibility of a cultural, economic and, in certain cases, political unification.

There may very well be states in space of some sort, in that there will need to be some form of self-governance. In some way, shape, or form, there must be human mechanisms to enact law, to interpret law, and to execute law. Someone has to make decisions and to be accountable for them. The buck has to stop on someone's desk. Gorove wrote $(1977, \text { p. } 218)^{36}$ :

The space treaties now in force have not abolished sovereignty or sovereign rights in outer space. The relevant Article II of the Outer Space Treaty only refers to sovereignty in connection with a ban on national appropriation. Nothing is said about prohibiting other forms or expressions of sovereignty or sovereign rights. In fact, the Outer Space Treaty provides that states shall bear international responsibility for national activities in outer space irrespective of whether such activities are carried out by governmental or nongovernmental entities. This provision presupposes exercise of some form of sovereign rights, jurisdiction or control by the state whose nationals are part of the space colony. Otherwise, it is hard to see how a state could be liable for activities over which it had absolutely no control.

However, what degree of sovereignty the space states may have in relation to the nation-states system on Earth, or in relation to each other, is an open question. There will be no nations in space. Nations are defined by distinct ethnicities, languages, and cultures, originating, developing, and largely contained within distinct geographic areas. How distinct will be one lunar settlement from another, or from a Martian settlement? Sovereignty will be localized, and the shape that sovereignty takes will be influenced by the social organization of these settlements. The conceptual groundwork for such organization can and should begin before significant numbers of people are working in space on a regular basis. Whitney ${ }^{37}$ wrote (1984, pp. 12-13):

The relatively new idea of space settlements has attracted the interest of few social scientists; publications are rare and appear in disparate sources. Much of the material that is published on "space colonies," "space humanization," "human communities in space, etc., is written by technologists and reveals little significant knowledge about the complexities of human society....

We need an international cadre of space planners. Rather than replicating and concretizing political economic forms of the past through haphazard and string-budget planning efforts... space warrants international planning and organization. I am calling for... a redevelopment and [re]arrangement of Humankind's priorities: a 21st century political economy. 
Jurisdiction will extend only over territory being used for productive activity. Forms of local sovereignty will develop under the international treaty regime. Extraterrestrial settlements will start out as international projects in many cases, and will gradually develop self-governance, but not complete sovereignty. Settlements may develop within a confederation or an integrated federal system, or alternatively, sovereignty may be vested in entities resembling city-states, and possibly city-leagues of voluntarily-shared sovereignty will develop.

Since any resources not being used are the commons, and according to Article I of the Outer Space Treaty, "there shall be free access to all areas of celestial bodies," there can be no fencing off of large areas for exclusion. Since no large areas can be appropriated, no large areas need be defended against encroachment. Thus there will be no need of a military force, and no need of a strong central government to support and organize such a force. Sovereignty will be vested in the people, and aggregated only to a local level as necessary for self-governance to provide police, fire, health, and infrastructure services for each settlement. Of course, wherever there is interstate commerce there is the potential for piracy, and an interplanetary police force may be necessary to suppress that evil. It might be argued that populations in isolation on these far-flung worlds will develop distinct cultures over time, that new national identities will form, just as they did in the New World, and thus the evils of the Westphalian system will proliferate throughout the solar system. Militating against this, however, is the fact that these entities will not have developed as isolated appendages of mercantile empires; the capitalist multiworld-system will bind them together into a web of production chains and trading relationships. Also, whereas communication between American colonies and Europe took months, and even between colonies took weeks, information will flash across the inner solar system in a matter of minutes. Marshal McLuhan's (1962) "global village" will become the "solar village."

The basic unit of the interplanetary political system may evolve over time, from individual settlements to geographically larger agglomerations, but there will probably remain an overarching regime, such as is envisioned in the Moon Agreement. This regime may gradually evolve into an interplanetary "government," but with muchrestricted powers as compared to those associated with nation-states. Friedrichs's new medievalism might well characterize the governance of the solar system, a complicated web of societal identities, held together by the competing organizational claims of the interplanetary market economy, the interplanetary regime established by treaty, and localized sovereignty. Yet the term "medievalism" has the connotation of something very backward, and in a way, there will be a backward motion as well as a forward motion, but it will be a backward motion informed by forward thinking. Whereas the Reformation led to the agglomeration of sovereignty from dynastic states to the national level, the devolution of sovereignty to the local level and to the individual would better express the ideals of the Enlightenment. Markoff $(1970)^{38}$ wrote:

Space lawyers have to help develop the new legal order in space and on celestial bodies. They should endeavour to prevent space contamination with national rivalries and disputes. Instead of acting like dinosaurs in [the] space age, jurists have to impose upon politics an evolution towards a real common use and exploitation of the resources of space and celestial bodies, in the interests and for the benefit of all countries. A new pattern for a better future on the Earth, too, will be created therewith, in full harmony with the positive international law of space.

A contradiction in the outer space private property rights movement is that it is ideologically based in economic liberalism; however, the methods it advocates are realist, in that it dismisses the importance of treaties, advocating their contravention or US withdrawal from them. Global liberalism requires a stable international legal regime, and space liberalism will also. To be successful, it needs to be institutional in its approach. Another contradiction in the space libertarian schemes for private property rights is that in espousing the assertion of the nation-state over the international community, the effect is to extend the nation-state into outer space, to the detriment of local sovereignty. In contrast, the common law regime of the Regency of United Societies in Space would obviate much of the need for sovereign regimes.

In outer space, where nation-states do not and cannot exist, a new paradigm of sovereignty will have an unfettered opportunity to take root and to flourish. We may see representative government as known on Earth give ground to something approaching the Athenian model of direct democracy. Settlements will start out small enough for each adult to participate in the political decision-making process without the need for an elected legislature of representatives to mediate. As these settlements grow, the continuing development of information technology may enable individuals in these highly-educated populations to process more of the types of information pertinent to political decisions. A few centuries from now, whatever new forms of governance, new conceptions of rights, and new norms of state behavior that have been invented on the Moon, Mars, and elsewhere in the solar system, may be introduced to "old Earth." 


\section{N. The Future Ecology of Capitalism}

A specter is haunting the solar system. While progressives blame the voracious appetite of the capitalist system for accelerating the depletion of the world's resources and the destruction of the environment, economic liberals and enviro-capitalists claim that "wealthier is healthier," that more citizens of more affluent societies demand a better environment in which to live. In 1991, economists first reported a systematic relationship between income changes and environmental quality, known as the Environmental Kuznets Curve (EKC). When first unveiled, EKCs revealed a surprising outcome: Some important indicators of environmental quality such as the levels of sulfur dioxide and particulates in the air actually improved as incomes and levels of consumption went up (Yandle et al. 2002). U-shaped relationship between several important air pollutants and national income (Harbaugh et al. 2001)

New technologies may alleviate some of the problems. The capitalist drive for efficiency may save it from consuming the entire planet and drive it toward developing more efficient ways of using the limited resources of the planet. Economic liberals argue that successful corporations can afford to invest in more environmentally-friendly technologies, but it is not clear that they have the incentive to do so. This may require melding environmental policy and market forces in such a way that the environmental costs of manufacturing a product are factored into its sale price, and the environmental cost of operating a product is amortized over its life cycle. It may also require a more environmentally-conscious consumerism that alters the forces of the marketplace to favor products with smaller environmental footprints. Even in the best case scenario, there will probably be significant costs to changing the essential structure of the economic system. It is not clear how we get there from here, who makes the decisions, and how the costs are distributed.

There are limits to growth; however, these are not hard and fast, but are defined in terms of market and social forces and technology. There is a limit to the number of internal combustion automobiles that can be operated on this planet for a given environmental load. Fuel cell technology, being much cleaner, will increase the limit on automobiles; however, the electrical power needed to electrolyze water into hydrogen and oxygen will probably still be supplied by fossil fuel-burning plants for the next several decades. Fusion power generation will increase our limits even further; however, twenty-five years ago, it was estimated that the commercial application of this technology was twenty to fifty years away, and unfortunately, that is still the estimate.

It is true that we only have one Earth, yet we need not be limited to it forever. In the past, the political left has regarded the space program as "macho and polluting (McDougall 1985)." ${ }^{.39}$ This is unfortunate, for many advocates for a vigorous space program are socially progressive and environmentally conscious. More to the point, for decades now, remote sensing from orbit has allowed us to discover new resources and manage them more intelligently, and to monitor environmental degradation.

Looking forward, the development of extraterrestrial resources will certainly not provide complete solutions to overpopulation, over-consumption, resource depletion, and environmental degradation, but it will increasingly become part of the solution. The resources of the solar system are not available to us with current chemical propulsion technology, nor does this technology make it feasible for any but a handful of people to emigrate from Earth. Nuclear thermal propulsion (NTP), while more efficient, would engender much of the same social resistance as nuclear fission power plants (NTP technology was developed in the 1960s for human interplanetary missions, but has never been used in actual spaceflight). Even so, NTP would probably enable only limited extraterrestrial resource utilization, perhaps employing a few thousand or tens of thousands of off-planet workers. The dramatic breakout will probably have to wait for fusion propulsion technology, which will probably lag the development of Earth-based commercial fusion power generation by several decades. Fusion propulsion, of course, is only a gleam in the eyes of engineers, and its implications cannot yet be well understood. Potentially, however, it could enable the full flowering of a transplanetary economy in which tens of millions of people live and work off-planet in its initial stages. While it is doubtful that even this level of technology will enable enough people to emigrate from Earth to reduce its population by any appreciable degree, it should make it economically feasible to move a

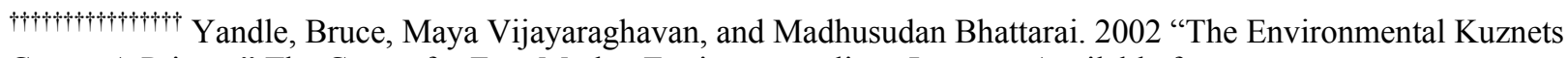
Curve: A Primer," The Center for Free Market Environmentalism. Internet. Available from http://www.perc.org/perc.php?subsection=9\&id=688; accessed 23 February 2006.

1+m+tom+ta Harbaugh, William T., Arik Levinson, and David Molloy Wilson. 2001. "Reexamining the Empirical Evidence for an Environmental Kuznets Curve,” 27 February. Internet. Available from http://harbaugh.uoregon.edu/Papers/EnvironmentalKuznetsCurve.pdf; accessed 23 February 2006. 
considerable portion of environmentally-destructive industries off-planet. The Moon, Mars, and the asteroids will become the new economic periphery, as core-like, predominately low-pollution, economic activity expands to encompass most of the Earth (the ultimate EKC). No doubt, new socioeconomic and political problems will arise in this multiplanetary venue, even as we solve some of our old ones. In any case, it is possible that the crisis in capitalism that Wallerstein foresees might either be averted or informed by economic expansion into the solar system, if we can keep the world economic system from hitting the wall before then.

While mainstream economics takes the market economy as a given, Wallerstein points out that capitalism is an historical phenomenon; it had a beginning, and presumably it will have an end. It played a role in transforming medievalism into the Westphalian system and spawned the Industrial Revolution. Nation-state policy interaction with capitalism has yielded in turn mercantilism, trade liberalism, imperialism, fascism, and neoliberalism. And, capitalism has morphed with each of these political changes, adapting to the political environment. All of these changes have occurred within the lifespan of the Westphalian system. It may not be possible to predict what capitalism will morph into under an interplanetary political environment characterized by new medievalism, but it is certainly possible to predict that it will morph. Given the many phases it has experienced within the Westphalian system, the outcome of its transformation under new medievalism might well be unrecognizable to us. This suggests that we are in little danger of approaching the "End of History" any time soon, that there is more socioeconomic evolution to come as the human species colonizes new ecological niches in the Cosmos. There will be new struggles over modes of production and political ideology, but we may hope that the history of the future will be far less bloody.

\section{Acknowledgments}

This research was supported in part by National Science Foundation grants SBR-9729957 and SES-9944042.

\section{References}

${ }^{1}$ Robertson, R. 1992. Globalization: Social Theory and Global Culture. Newberry Park, California, Sage.

${ }^{2}$ Nolan, P. and Lenski, G. 1999. Human Societies: An Introduction to Macrosociology, $8^{\text {th }}$ edition. New York, McGraw-Hill College.

${ }^{3}$ Peterson, R.D., Wunder, D.F., and Mueller, H.L. 1999. Social Problems: Globalization in the $21^{\text {st }}$ Century. Upper Saddle River, New Jersey, Prentice-Hall, Inc.

${ }^{4}$ Drexler, K.E. and Peterson, C. (with Pergamit, G.). 1991. Unbounding the Future: the Nanotechnology Revolution. New York, Quill William Morrow.

${ }^{5}$ Dudley-Flores, M. and Gangale, T. "Astrosociology: To Boldly Go - Where Sociology Is Needed the Most and Is Afraid to Tread," Pacific Sociological Association Conference, 29 March - 1 April 2007, Oakland, California.

${ }^{6}$ Duncan, O.D. 1959. "Human Ecology and Population Studies," The Study of Population, edited by Philip M. Hauser and Otis Dudley Duncan, Chicago, Illinois, University of Chicago Press, pp. 678-716.

${ }^{7}$ Nolan, P. and Lenski, G. 1999. Human Societies: An Introduction to Macrosociology, $8^{\text {th }}$ edition. New York, McGraw-Hill College.

${ }^{8}$ Dudley-Rowley, M. 1999. "The Outward Course of Empire: The Hard, Cold Lessons From American Involvement in the Terrestrial Polar Regions," Proceedings of the Founding Convention of the Mars Society, edited by Robert M. Zubrin and Maggie Zubrin, Vol. 1, Univelt, Incorporated, San Diego, California.

${ }^{9}$ Gangale, T. "To Boldly Own What No One Has Owned Before: Property Rights and the Development of Outer Space," Master's Thesis, International Relations Dept., San Francisco State Univ., San Francisco, California, 2006.

${ }^{10}$ Michaud, M. A. G. 1986. Reaching for the High Frontier: The American Pro-Space Movement, 1972-1984. New York, Praeger.

${ }^{11}$ Launius, R. D. 2000. "Project Apollo in American Memory and Myth." In Proceedings of Space 2000, edited by Stewart W. Johnson, Koon Meng Chua, Rodney G. Galloway, and Philip I. Richter, American Society of Civil Engineers, Reston, Virginia, pp. 1-13.

${ }^{12}$ Anderson, P. 1963. "Territory." Analog, June.

${ }^{13}$ Nolan, P. and Lenski, G. 2006. Human Societies. Boulder, Colorado, Paradigm Publishers, p. 350.

${ }^{14}$ Sackrey, C. and G. Schneider with Knoedler, J. 2002. "John Kenneth Galbraith and the Theory of Social Balance. In Introduction to Political Economy, Cambridge, Massachusetts, Economic Affairs Bureau, Inc., pp.132-156.

${ }^{15}$ Dudley-Rowley, M. and Gangale, T. 2006. "Sustainability Public Policy Challenges of Long-Duration Space Exploration," AIAA Space 2006 Meeting Papers on Disc [CD-ROM], AIAA-2006-7489, Reston, Virginia.

${ }^{16}$ Launius, R. D. 2000. "Project Apollo in American Memory and Myth." In Proceedings of Space 2000, edited by Stewart W. Johnson, Koon Meng Chua, Rodney G. Galloway, and Philip I. Richter, American Society of Civil Engineers, Reston, Virginia, pp. 1-13

${ }^{17}$ United States Senate. 1980. "The Moon Treaty." Hearings Before the Subcommittee on Science, Technology, and Space of the Committee on Commerce, Science, and Transportation. 96th Congress, 2nd Session.

${ }^{18}$ Sykes, C.J. 1989. ProfScam: Professors and the Demise of Higher Education. Washington, D.C., Regnery Gateway. 
${ }^{19}$ Coutinho, J. de S. 1977. Advanced Systems Development Management. New York: John Wiley \& Sons, Inc.

${ }^{20}$ Schweller, R. L. 1994. "Bandwagoning for Profit: Bringing the Revisionist State Back In," International Security, Vol.19, Part 1, pp. 72-107.

${ }^{21}$ Gangale, T. 2007. "The Architecture of Time, Part 3: Project Management in Two-Dimensional Time," AIAA Space 2007 Meeting.

${ }^{22}$ Deffeyes, K.S. 2005. Beyond Oil, New York, Hill and Wang.

${ }^{23}$ Ibid

${ }^{24}$ Ibid

${ }^{25}$ Dudley-Rowley, M. and Colombano, S.P. 2004. "The Robosphere: The Conceptual Expansion of the Human Factors," AIAA Space 2004 Meeting Papers on Disc [CD-ROM], AIAA-2004-5842, Reston, Virginia.

${ }^{26}$ Dudley-Rowley, M. and Gangale, T. 2006. "Sustainability Public Policy Challenges of Long-Duration Space Exploration," AIAA Space 2006 Meeting Papers on Disc [CD-ROM], AIAA-2006-7489, Reston, Virginia.

${ }^{27}$ Dudley-Rowley, M. 1999. "The Outward Course of Empire: The Hard, Cold Lessons From American Involvement in the Terrestrial Polar Regions," Proceedings of the Founding Convention of the Mars Society, edited by Robert M. Zubrin and Maggie Zubrin, Vol. 1, Univelt, Incorporated, San Diego, California.

${ }^{28}$ Spruyt, H. 1994. "Institutional selection in international relations" International Organization, Vol. 48, Part 4.

${ }^{29}$ Gilpin, R. 2000. The Challenge of Global Capitalism: The World Economy in the 21st Century. Princeton, Princeton University Press.

${ }^{30}$ Steger, M. B. 2002. Globalism. Lanham, Maryland, Rowman \& Littlefield Publishers, Inc.

${ }^{31}$ Huntington, S. P. 1993. "Clash of Civilizations." Foreign Affairs, Summer, Vol. 72, Part 3, p. 22.

${ }^{32}$ Friedrichs, J.. 2001. "The Meaning of New Medievalism.” European Journal of International Relations, Vol. 7, Part 4, pp. 475-502.

${ }^{34}$ Whitney, S. B. 1984. "Space Political Economy: Integrating Technology and Social Science for the 1990s," Third Annual Space Development Conference, San Francisco, April.

${ }^{35}$ Vázquez, Seara. 1965.

${ }^{36}$ Gorove, S. 1977. Studies in Space Law: Its Challenges and Prospects, Leyden, The Netherlands, A. W. Sijthoff.

${ }^{37}$ Whitney, S. B. 1984. "Space Political Economy: Integrating Technology and Social Science for the 1990s." Third Annual Space Development Conference, San Francisco, April.

${ }^{38}$ Markoff, G. 1970. "Space Resources and the Scope of the Prohibition in Article II of the 1967 Treaty." Proceedings, 13th Colloquium on the Law of Outer Space, 81-83. American Institute of Aeronautics and Astronautics.

${ }^{39}$ McDougall, W. A. 1985. The Heavens and the Earth: A Political History of the Space Age, New York. Basic Books, Inc. 